\title{
Temperature shocks and welfare costs ${ }^{\text {is }}$
}

\author{
M. Donadelli, M. Jüppner, M. Riedel, C. Schlag* \\ Research Center SAFE, House of Finance, Goethe University Frankfurt, Germany
}

\section{A R T I C L E I N F O}

\section{Article history:}

Received 10 November 2016

Revised 23 June 2017

Accepted 6 July 2017

Available online 21 July 2017

\section{JEL classification:}

E30

G12

Q0

\section{Keywords:}

Temperature shocks

Long-run growth

Asset prices

Welfare costs

Adaptation

\begin{abstract}
A B S T R A C T
This paper examines the welfare implications of rising temperatures. Using a standard VAR, we empirically show that a temperature shock has a sizable, negative and statistically significant impact on TFP, output, and labor productivity. We rationalize these findings within a production economy featuring long-run temperature risk. In the model, macro-aggregates drop in response to a temperature shock, consistent with the novel evidence in the data. Such adverse effects are long-lasting. Over a 50-year horizon, a one-standard deviation temperature shock lowers both cumulative output and labor productivity growth by 1.4 percentage points. Based on the model, we also show that temperature risk is associated with non-negligible welfare costs which amount to $18.4 \%$ of the agent's lifetime utility and grow exponentially with the size of the impact of temperature on TFP. Finally, we show that faster adaptation to temperature shocks results in lower welfare costs. These welfare benefits become substantially higher in the presence of permanent improvements in the speed of adaptation.
\end{abstract}

(c) 2017 Elsevier B.V. All rights reserved.

\section{Introduction}

Long-term global changes in temperature and precipitation indicate that our entire planet is undergoing a climate change. Despite a decades-spanning debate, climatologists and economists alike have not reached a consensus about the long-term economic effects of this dramatic development (see Pindyck, 2013). In this paper, we quantify the effect of temperature shifts on aggregate productivity, labor, consumption, and asset prices. More specifically, we integrate time-varying temperature dynamics into a production-based model featuring recursive preferences, long-run risk, and investment adjustment costs. This setup provides us with the opportunity to expand the scope of the analysis considerably beyond what is possible in an endowment-based model, e.g., when it comes to the dynamics of investment and labor.

Temperature statistics suggest that the average temperature level has been increasing over the last century both globally and among major advanced economies. Using a bivariate vector autoregression (VAR) analysis and data on U.S. temperature, we observe a statistically significant and long-lasting negative impact of temperature on total factor productivity (TFP). Quantitatively, a one-standard deviation temperature shock leads to a drop in one-year future aggregate U.S. TFP growth by around 0.2 percentage points (pp). When including other macroeconomic variables, the effect on TFP growth becomes (statistically) weaker. However, we are still able to observe an overall negative impact on the economy as indicated by a

\footnotetext{
An earlier version of this paper circulated under the title "How Costly is Global Warming? Implications for Welfare, Business Cycles, and Asset Prices". The authors gratefully acknowledge research and financial support from SAFE, funded by the State of Hessen initiative for research LOEWE

* Corresponding author.

E-mail addresses: donadelli@safe.uni-frankfurt.de (M. Donadelli), jueppner@safe.uni-frankfurt.de (M. Jüppner), riedel@safe.uni-frankfurt.de (M. Riedel), schlag@finance.uni-frankfurt.de (C. Schlag).
} 
decrease in future consumption growth $(-0.3 \mathrm{pp})$, output growth $(-0.5 \mathrm{pp})$, investment growth $(-1 \mathrm{pp})$ and labor productivity growth (-0.5pp), consistent with recent empirical evidence (see Colacito etal., 2016). By accounting for the dynamics of asset prices in the VAR estimation, the negative effect of temperature on future TFP growth remains qualitatively unaffected.

We explain our empirical findings in a production-based model featuring temperature dynamics. By calibrating the model to data on the evolution of temperature in the U.S., we are also able to estimate the welfare losses associated with temperature shocks. Our findings show that, in the long-run, rising temperature has strong adverse effects on key macroeconomic aggregates, productivity, and asset valuations. Further, our model provides a theoretical equilibrium explanation for the negative effect of temperature increases on labor productivity found in empirical studies (see Deryugina and Hsiang, 2014; Park, 2016).

Greenhouse gas (GHG) emissions due to human activities are the most important cause of the climatic developments that followed the Industrial Revolution in 1750 (Hartmann et al., 2013). Greenhouse gases affect atmospheric composition, leading to a rise in surface temperature on earth which, in turn, increases the probability of certain types of extreme weather events, such as heavy rainfalls, floods, hurricanes, or droughts (see, e.g., Villarini et al., 2013). One of the most significant greenhouse gases is carbon dioxide which is released into the atmosphere due to fossil energy usage. There is an ongoing debate on how to contain $\mathrm{CO} 2$ concentration most effectively, and a popular approach is to estimate the overall welfare costs of $\mathrm{CO} 2$ emissions in order to impose a fossil fuel taxation that ensures a balance between economic growth and GHG emission (see Golosov et al., 2014).

A growing number of studies investigates the empirical linkage between economic performance and weather events. Hsiang (2010), for instance, documents that industries such as agriculture and tourism, where relocation is either completely impossible or at least very expensive, are affected most by higher temperatures and increasing rainfall. Schlenker and Roberts (2009) instead observe that higher temperatures have non-linear effects on crop yields, i.e., above a certain threshold higher temperatures no longer increase yields but are extremely detrimental. Other recent empirical findings suggest also that extreme whether events may lead to an increase in mortality (Deschênes and Moretti, 2009), a reduction in labor supply (Zivin and Neidell, 2014), and a general drop in firms' productivity (Cachon et al., 2012).

Pricing the risks associated with climate change is essential for comparing the costs for different measures to contain the adverse climatic developments. A popular approach is to use so-called integrated assessment models (IAMs) (Nordhaus, 2008; Stern, 2007). However, the usefulness of these models in estimating the social cost of climate change and increasing carbon emissions is at the center of an ongoing debate. For example, Pindyck (2013) criticizes IAMs as having little theoretical or empirical foundation. He finds that the model inputs, such as parameter values and functional forms, are chosen arbitrarily, while the choice of the discount rate reaches an ethical dimension. ${ }^{1}$ Furthermore, he stresses that the majority of economic studies on climate change imposes a loss function on the level instead on the growth rate of output. This assumption does not seem appropriate, since climate change is likely to have a permanent economic impact, e.g., through the destruction of ecosystems, deaths from weather extremes, or social disruption, and it also contradicts the empirical findings provided by Dell et al. (2012). According to Revesz et al. (2014), current models also omit adverse effects on labor productivity, productivity growth, and the value of the capital stock. Finally, one can as well criticize the deterministic nature of IAMs used for policy analyses, since uncertainty about economic and climate conditions is likely to affect people's behavior. This latter point is addressed by Golosov etal. (2014) and Cai et al. (2015) who study climate change within a dynamic stochastic general equilibrium (DSGE) framework. However, as in the traditional IAMs, they model adverse effects of temperature by means of a damage function on the level of GDP.

Our DSGE model responds to the issues raised by these critics in a straightforward way. It builds on the production economy framework introduced by Croce (2014) who shows that long-run productivity risks coupled with preferences for early resolution of uncertainty have strong implications for macroeconomic quantities and asset prices. ${ }^{2}$ We augment the model in Croce (2014) by temperature dynamics as suggested by Bansal and Ochoa (2011). Specifically, temperature shocks negatively impact the long-run productivity growth in the economy, and this assumption is strongly supported by empirical evidence. $^{3}$ This link between temperature and TFP ensures that the impact of temperature is actually on the growth rate of macro-aggregates and not on their level. Furthermore, in our general equilibrium framework the agent chooses labor input optimally. This model feature allows us to investigate the potential effects of temperature changes on employment and labor productivity.

\footnotetext{
${ }^{1}$ According to Pindyck (2013) one might argue that it is unethical to value the welfare of future generations lower than our own, which implies that the ethically appropriate discount rate would equal zero. However, Weitzman (2007) argues that this assumption is inconsistent with actual individual behavior.

${ }^{2}$ In this respect, our framework relates to recent studies aimed at matching asset prices via the use of production economies embodying different risk channels. Hitzemann (2016), for instance, shows that oil productivity shocks may help capturing statistical features of aggregate and sectoral stock returns. However, his production economy does not generate a sizable equity market returns volatility (see also Croce, 2014; Kung and Schmid, 2015; Donadelli and Grüning, 2016). Favilukis and Lin (2016) solve this puzzle by introducing an infrequent wage resetting labor market mechanism and a CES production function. Gomme et al. (2011) show that a standard RBC model with stochastic relative price of investment goods can (i) produce a relatively high equity return volatility and (ii) account for the volatility of the return to business capital, which in the data is lower than the volatility of the S\&P 500, even in the absence of habit persistence or any type of frictions.

${ }^{3}$ Unlike standard IAMs, our DSGE model explicitly incorporates uncertainty about the future through the introduction of temperature shocks (see also Farmer et al., 2015).
} 
In the spirit of Bansal and Ochoa (2011), we parametrize our production-based asset pricing model using results from the bivariate VAR analysis for temperature and TFP growth and set the model parameters in order to match asset prices, macroeconomic quantities and U.S. temperature statistics. Since positive temperature shocks reduce TFP growth instantaneously, consumption, output, investment, and labor productivity growth decline both in the short-run and over a longer horizon, which leads to lower asset valuations as well. An important feature of our model is, thus, that it endogenously generates the negative effect of rising temperatures on labor productivity found in the data (see Deryugina and Hsiang, 2014; Park, 2016). When we express the economic costs of higher temperatures in terms of additional consumption needed to compensate the agent for temperature risk, we find that welfare costs are quite sensitive to the degree to which temperature changes impact TFP growth. Increasing the negative impact of temperature in absolute terms makes welfare costs rise exponentially, which provides further evidence for the dramatic impact that temperature-related climate change can have on the real economic activity. Specifically, welfare costs amount to $18.4 \%$ of composite consumption in our benchmark economy, but if we allow for higher adverse temperature effects, which are still in the range of empirical estimates, those costs amount to $36.8 \%$. Moreover, in the model, a rise in temperature is found to have long-lasting negative effects on output and labor productivity growth. Over a 50-year horizon, a single one-standard deviation shock reduces both cumulative output and labor productivity growth by 1.4pp. Finally, we study the welfare implications of varying adaptation efforts by agents in response to temperature changes. A faster adaptation to positive temperature shocks results in lower welfare costs and vice versa. Policies aiming at increasing the speed of adaptation permanently bring substantial benefits in terms of welfare, while a permanently slower adaptation can have dramatic consequences with exponentially increasing welfare losses.

The remainder of this study is organized as follows. Section 2 provides empirical evidence on the effects of temperature shifts on macroeconomic aggregates and asset prices. Section 3 describes the model. The benchmark calibration and main quantitative results are presented in Section 4 . Section 5 concludes.

\section{Empirical analysis}

In this section, we present our empirical findings on temperature changes and their effect on U.S. macroeconomic and financial variables. We show that a positive shock to U.S. temperature has an adverse effect on the growth rate of main macroeconomic aggregates. Moreover, rising temperatures affect asset prices. These results motivate and provide empirical support for our production-based model featuring temperature dynamics.

\subsection{Temperature shocks and the U.S. macroeconomy}

Recent studies show that increases in temperature harm real economic activity (Bansal and Ochoa, 2011; Cai etal., 2015; Colacito etal., 2016; Dell et al., 2012; Dua et al., 2017). We contribute to this evidence by investigating the impact of rising temperatures on macroeconomic variables and asset prices. Specifically, we examine the effects of a rise in U.S. temperature on U.S. TFP growth, consumption growth, output growth, investment growth, labor productivity growth, price-dividend ratio, and risk-free rate. As in Croce (2014), we use the private business sector multifactor productivity index of the Bureau of Labor Statistics (BLS) as a proxy for the TFP. All other real macro-aggregates are obtained from the Bureau of Economic Analysis (BEA). In terms of asset pricing data, we obtain the risk-free rate from the Kenneth-French data library and the market price-dividend ratio is based on Robert J. Shiller's online dataset. The U.S. temperature (expressed in degrees Fahrenheit) comes from the NOAA National Centers for Environmental information. All data are annual and span the period from 1950 to 2015. Additional details on data are reported in Appendix A. Our decision to focus on the U.S. is motivated by two main reasons. First, U.S. data provide us with longer time series and, thus, more data points for the VAR estimations, and second this approach allows us to compare our empirical evidence with the recent findings of Colacito etal. (2016), who work with more granular, quarterly, U.S. data.

We start our analysis by estimating a bivariate VAR model for TFP growth and temperature dynamics. Fig. 1 (Panel A) shows the impulse-response function of TFP growth to a one-standard deviation shock in temperature. The impulse response is based on the Cholesky orthogonalization of the VAR model with one lag in which temperature shocks are ordered first. In line with existing evidence, our results suggest that a temperature shock reduces productivity growth. The observed negative effect is rather persistent, lasting for more than five years and is statistically significant at the $10 \%$ level after two years. ${ }^{4}$

Climate research argues that there is a strong connection between temperature increases and precipitation (see, among others, Allen and Ingram, 2009; Solomon et al., 2009). Moreover, recent findings suggest that rainfall undermines economic growth (Barrios etal., 2010). To account also for this possible side-effect of temperature increases, we repeat our simple analysis by looking at the precipitation level in the U.S. and its effect on TFP growth. We shed, thus, new light on the relationship between rising temperatures, precipitation and real economic activity by estimating a bivariate VAR of annual TFP growth and precipitation in the U.S. analogous to the one for temperature and TFP. The results in Fig. 1 (Panel B) suggest that there is a negative effect of higher precipitation on TFP growth. The impact is slightly less persistent compared to a U.S. temperature shock.

\footnotetext{
${ }^{4}$ Note that the U.S. temperature series we use in our empirical analysis is stationary over the sample period from 1950 to 2015 . Therefore, we do not include a trend in our VAR analysis and do not account for any co-integration relations between variables. Results from the augmented-Dickey-Fuller and Phillips-Perron unit root tests are available upon request.
} 
PANEL A: $\mathrm{T} \rightarrow \triangle \mathrm{TFP}$

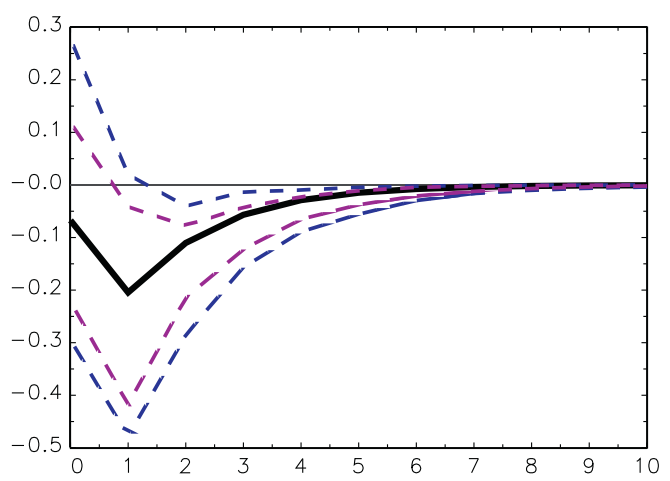

PANEL B: PRECIPITATION $\rightarrow \Delta$ TFP

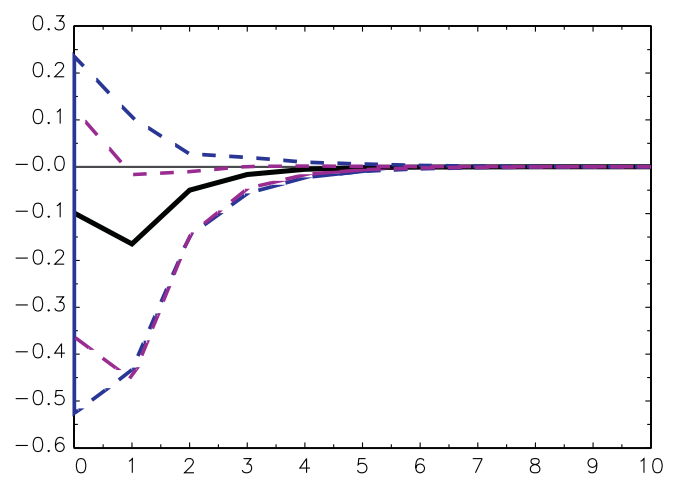

Fig. 1. Impulse response of TFP to temperature and precipitation.

Notes: This figure depicts the "Cholesky" orthogonalized impulse response of TFP growth to a temperature (Panel A) and precipitation (Panel B) shock. Solid "black" line: estimated impulse response. Dashed "blue" lines: 90\% bootstrapped confidence bands. Dashed "magenta" lines: 68\% bootstrapped confidence bands. The values reported are deviations from the steady state (i.e., long-run mean) in percentage points. TFP growth is computed from the private business sector multifactor productivity index provided by the BLS. Data on U.S. temperature (expressed in degrees Fahrenheit) and U.S. precipitation (expressed in Inches) are from the NOAA National Centers for Environmental information. Data are annual and span the period from 1950 to 2015 . Additional details on data are given in Appendix A. (For interpretation of the references to color in this figure legend, the reader is referred to the web version of this article.)

Although weather-related phenomena such as increasing rainfall, droughts, storms, or natural disasters in general will certainly have a non-negligible impact on the aggregate economy, we do not model them explicitly. We believe that we capture the first order effect of temperature increases by looking at temperature dynamics as a broad weather indicator since many natural disasters are known to be triggered via excessively increasing temperatures. ${ }^{5}$

To assess the impact of temperature shocks on the whole macroeconomy and to compare our model results to the data in Section 4, we augment the bivariate model by consumption, output, investment, and labor productivity growth. Fig. 2 shows that overall temperature has a negative impact on future macroeconomic variables. One year after the temperature shock, TFP growth declines by $0.2 \mathrm{pp}$, consumption growth by $0.3 \mathrm{pp}$, GDP growth by $0.5 \mathrm{pp}$, investment growth by more than $1 \mathrm{pp}$, and labor productivity growth by $0.5 \mathrm{pp}$. The detrimental effects on future TFP are less significant but still persist when additional macroeconomic variables are taken into account. Future GDP and labor productivity drops are significant at $10 \%$. The lagged effect of a temperature shock on the economic variables does not come at a surprise as the shock does not affect all sectors homogeneously and, thus, propagates only gradually across the economy. This intuition is confirmed by Barrot and Sauvagnat (2016) who show that firm-specific shocks to suppliers, induced by natural disasters, have large short-term adverse effects on sales growth of their customers over the four consecutive quarters.

We acknowledge that the estimated temperature effects are relatively large compared to the findings of related studies. This might be due to the fact that other studies employ panel data in their analysis and account for variability across regions and time periods. One of the most turbulent time periods in our sample is the Great Recession and its repercussions. In order to investigate its effect on our results, we re-run our VAR using data for the period 1950-2007. Impulse responses from this robustness test are reported in Fig. B.1 in Appendix B and suggest slightly lower temperature adverse effects - over the first three years - for all macroeconomic variables except investment. ${ }^{6}$

The results of the preceding VAR estimations are based on the assumption that temperature is the "most exogenous" variable and, thus, ordered first in the VAR model. As a robustness test, we also compute "generalized" impulse responses that do not impose theoretical assumptions on the ordering of variables. Impulse responses for TFP growth and other macroaggregates are shown in Fig. B.2 in Appendix B. Responses are less significant but the direction and size of temperature effects are basically unchanged. Following a temperature shock, both TFP growth and the remaining macro quantities drop. ${ }^{7}$

\footnotetext{
5 The extension of our production-based model by adding natural (rare) disasters is left for future research.

6 We obtain similar estimates if we include a dummy variable for the Great Recession period in the full sample. Despite the relatively large future effect (i.e., two years after the temperature shock), it is noteworthy to mention that the temperature effect on contemporaneous GDP growth is of similar size as in Colacito et al. (2016) for both, the full and the shorter sample period.

7 As pointed out by Colacito etal. (2016), it is difficult to obtain highly significant results for annual temperature changes on the aggregate economy because seasonal and regional effects can be different. However, the authors find that negative effects dominate when aggregating seasonal and regional contributions. Our results confirm this finding by indicating a negative impact of rising temperatures on aggregate macroeconomic variables at the annual level.
} 

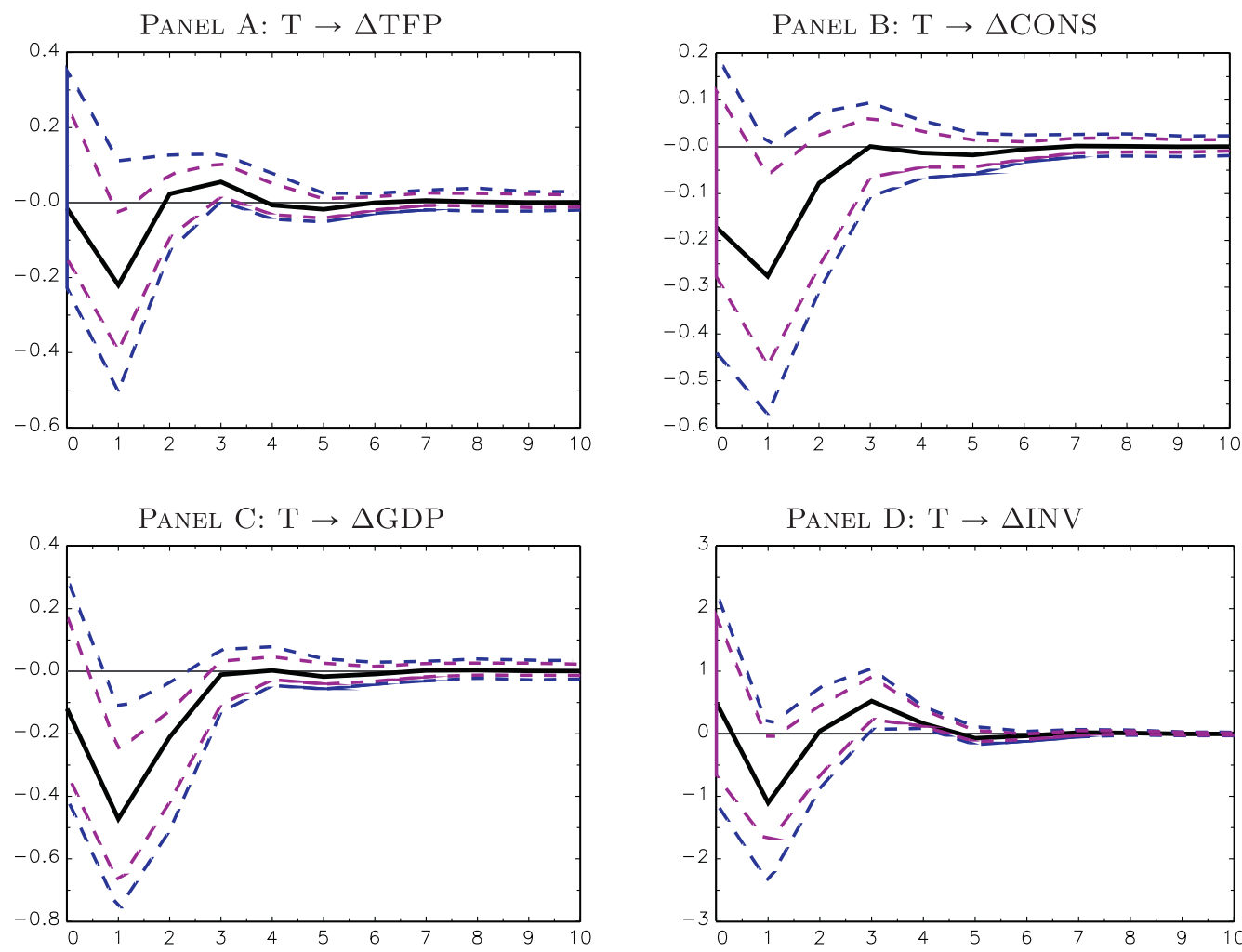

PANEL E: $\mathrm{T} \rightarrow \Delta \mathrm{LP}$

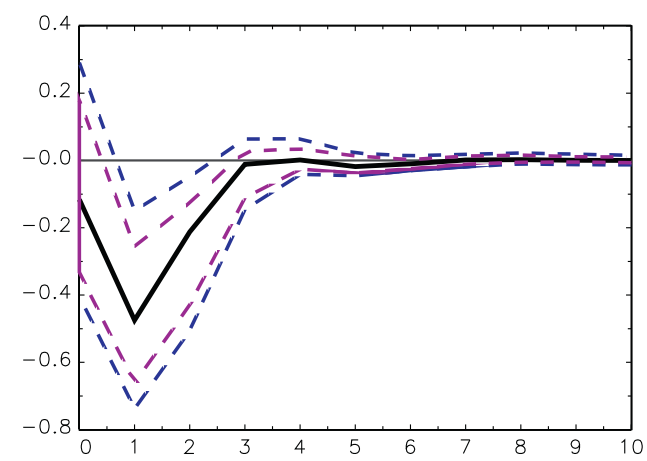

Fig. 2. Impulse response of macro-aggregates to temperature.

Notes: This figure reports "Cholesky" orthogonalized impulse responses of TFP growth (Panel A), consumption growth (Panel B), output growth (Panel C), investment growth (Panel D), and labor productivity growth (Panel E) to a temperature shock. Solid "black" lines: estimated impulse responses. Dashed "blue" lines: 90\% bootstrapped confidence bands. Dashed "magenta" lines: 68\% bootstrapped confidence bands. The values reported are deviations from the steady state (i.e., long-run mean) in percentage points. The VAR(1) model includes U.S. temperature, TFP growth, consumption growth, GDP growth, investment growth, and labor productivity growth, in this order. A constant is included. TFP growth is computed from the private business sector multifactor productivity index provided by the BLS. All the other macroeconomic variables are taken from the U.S. Bureau of Economic Analysis. The U.S. temperature (expressed in degrees Fahrenheit) is from the NOAA National Centers for Environmental information. Data are annual and span the period from 1950 to 2015. Additional details on data are given in Appendix A. (For interpretation of the references to color in this figure legend, the reader is referred to the web version of this article.)

\subsection{Temperature shocks, productivity and asset prices}

To confirm that our findings on the macroeconomic effects of temperature shocks are robust to the inclusion of additional variables that might affect productivity growth, we follow the tradition of the long-run risk literature by controlling for lagged risk-free rate, lagged price-dividend ratio, and lagged productivity growth (see Bansal etal., 2007; Croce, 2014). Impulse responses, in which temperature is ordered last, are presented in Fig. 3. TFP growth still reacts negatively to a tem- 

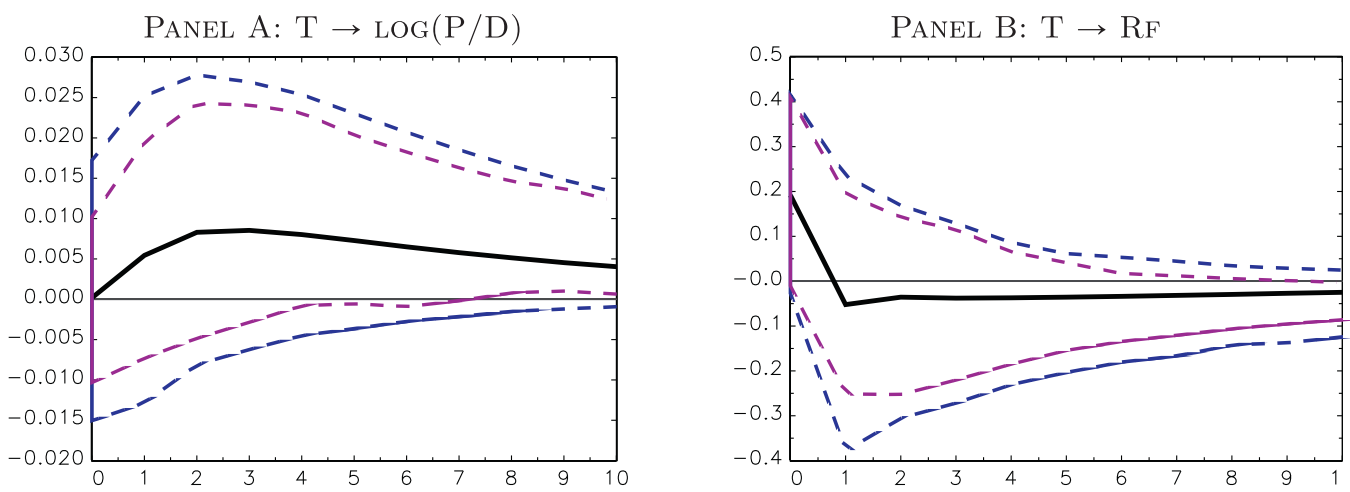

PANEL $\mathrm{C}: \mathrm{T} \rightarrow \triangle \mathrm{TFP}$

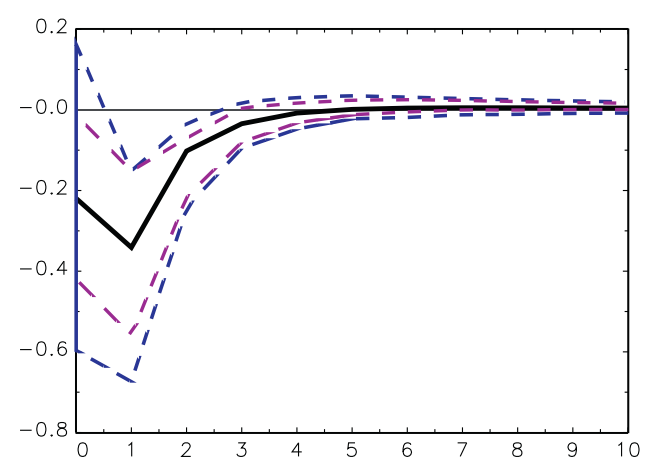

Fig. 3. Impulse response of asset prices to temperature.

Notes: This figure reports "Cholesky" orthogonalized impulse responses of market price-dividend ratio (Panel A), risk-free rate (Panel B), and TFP growth (Panel C) to a temperature shock. Solid "black" lines: estimated impulse responses. Dashed "blue" lines: 90\% bootstrapped confidence bands. Dashed "magenta" lines: $68 \%$ bootstrapped confidence bands. The values reported are deviations from the steady state (i.e., long-run mean) in percentage points. The VAR(1) model includes U.S. temperature, log of price-dividend ratio, risk-free rate, and TFP growth, in this order. A constant is included. TFP growth is computed from the private business sector multifactor productivity index provided by the BLS. The risk-free rate is obtained from the Kenneth-French data library and the market price-dividend ratio is computed from the Robert J. Shiller online dataset. The U.S. temperature (expressed in degrees Fahrenheit) is from the NOAA National Centers for Environmental information. Data are annual and span the period from 1950 to 2015. Additional details on data are given in Appendix A. (For interpretation of the references to color in this figure legend, the reader is referred to the web version of this article.)

perature shock both on impact and in the future (Panel C). The decline in TFP growth is still significant at the $10 \%$ level and lasts for four years. This is further confirmed by the entries in Table B.1, where we regress TFP growth on the price-dividend ratio, the risk-free rate, lagged productivity growth, and temperature for the periods from 1950 to 2015 and from 1960 to 2015. Over both periods, the effect of a rise in the level of temperature on TFP growth is relatively strong, negative, and statistically significant.

The dynamics of the responses of the risk-free rate and the price-dividend ratio are economically plausible, even if not statistically significant. In the case of the price-dividend ratio, two competing effects arise. Namely, lower investment leads to a reduction of the price of capital and equity, while the decrease in productivity growth reduces firms' profits and, thus, dividends. Our findings suggest that the latter effect dominates the former. Lower productivity also translates into a decreasing risk-free rate. In response to contracting equity markets, agents start to invest more into the risk-free asset, which implies a lower risk-free rate in the periods after the temperature shock.

Taken together, our empirical analysis suggests that positive temperature shocks have negative consequences on TFP growth and the growth rates of other macroeconomic aggregates. The negative response of TFP growth is robust to both the inclusion of additional macroeconomic and financial variables and the ordering of variables in the VAR. ${ }^{8}$

\section{Model}

Our empirical analysis shows that over the last century U.S. temperature had a negative and long-lasting impact on U.S. macroeconomic variables and, in particular, on TFP growth. To quantify the effects of temperature changes on business cycles

\footnotetext{
${ }^{8}$ Our main results are also robust to (i) the use of the utilization-adjusted TFP measure by Basu etal. (2006) as a proxy for aggregate productivity; (ii) the employment of global temperature as an alternative indicator of temperature dynamics; and (iii) the use of the level of precipitation as an alternative proxy for climate change-related phenomena.
} 
and financial markets, we develop a dynamic stochastic general equilibrium (DSGE) model. Specifically, we augment the production model featuring long-run productivity risk suggested by Croce (2014) with a stochastic process for temperature along the lines of Bansal and Ochoa (2011). The temperature dynamics are coupled with the evolution of TFP such that rising temperature has a negative impact on long-run productivity growth, the real economy and asset prices, as observed in the data.

\subsection{Households}

The representative household is equipped with recursive preferences, as in Epstein and Zin (1989):

$$
U_{t}=\left[(1-\beta) \tilde{C}_{t}^{1-\frac{1}{\psi}}+\beta\left(\mathbb{E}_{t}\left[U_{t+1}^{1-\gamma}\right]\right)^{\frac{1-1 / \psi}{1-\gamma}}\right]^{\frac{1}{1-1 / \psi}} .
$$

$\tilde{C}_{t}$ is a Cobb-Douglas aggregator for consumption $C_{t}$ and leisure $1-L_{t}$ (the remainder of a total time budget of 1 , when the amount of labor is $L$ ):

$$
\tilde{C}_{t} \equiv \tilde{C}\left(C_{t}, L_{t}\right)=C_{t}^{v}\left(A_{t}\left(1-L_{t}\right)\right)^{1-v},
$$

where $A_{t}$ denotes TFP. Multiplying leisure by the level of TFP ensures balanced growth and is interpreted as an adjustment for the standard of living (Croce, 2014). In this setting, $\gamma$ measures risk aversion, $\psi$ is the intertemporal elasticity of substitution (IES), and $\beta$ is the household's subjective discount factor. In line with the long-run risk literature, we assume that the representative household has preferences for early resolution of uncertainty, i.e., $\gamma>\frac{1}{\psi}$. Notice that under power utility (represented by $\gamma=\frac{1}{\psi}$ ) the impact of current shocks to productivity growth or temperature is always the same, irrespective of the persistence of these innovations. Loosely speaking, long-run productivity and temperature shocks will not be priced. Differently, under recursive preferences the household cares about uncertainty with respect to future utility and the risk generated by persistent innovations is priced. As a result, long-lasting shocks affect both prices and quantities (see Dew-Becker and Giglio, 2016).

In each period, the representative household chooses consumption $C_{t}$ and labor $L_{t}$ to maximize the utility function $U_{t}$ subject to the following dynamic budget constraint:

$$
C_{t}+B_{t+1}+\vartheta_{t+1}\left(V_{t}-D_{t}\right)=W_{t} L_{t}+B_{t} R_{t}^{f}+\vartheta_{t} V_{t},
$$

where $\vartheta_{t}$ denotes the number of equity shares in the firm held from time $t-1$ to time $t, V_{t}$ is the cum-dividend market value of the production sector, $D_{t}$ denotes dividends, $B_{t}$ is the number of bonds held from time $t-1$ to time $t, R_{t}^{f}$ is the gross risk-free rate, and $W_{t}$ represents the frictionless wage. ${ }^{9}$

The first-order conditions of the maximization problem lead to the following expression for the stochastic discount factor (SDF):

$$
M_{t, t+1}=\beta\left(\frac{\tilde{C}_{t+1}}{\tilde{C}_{t}}\right)^{1-\frac{1}{\psi}}\left(\frac{C_{t+1}}{C_{t}}\right)^{-1}\left(\frac{U_{t+1}^{1-\gamma}}{\mathbb{E}_{t}\left[U_{t+1}^{1-\gamma}\right]}\right)^{\frac{1 / \psi-\gamma}{1-\gamma}}
$$

The usual Euler equations for the cum-dividend value of one share of equity in the production sector and the gross risk-free rate can be written as

$$
V_{t}=D_{t}+\mathbb{E}_{t}\left[M_{t, t+1} V_{t+1}\right]
$$

and

$$
\frac{1}{R_{t}^{f}}=\mathbb{E}_{t}\left[M_{t, t+1}\right]
$$

\subsection{Firms}

The production sector admits a representative, perfectly competitive firm utilizing capital and labor to produce the output. The production technology is given by

$$
Y_{t}=K_{t}^{\alpha}\left(A_{t} L_{t}\right)^{1-\alpha},
$$

where $\alpha$ is the capital share, labor $L_{t}$ is supplied by the household, and $A_{t}$ is TFP. The capital stock evolves according to

$$
K_{t+1}=\left(1-\delta_{K}\right) K_{t}+G\left(\frac{I_{t}}{K_{t}}\right) K_{t},
$$

\footnotetext{
${ }^{9}$ In order to focus exclusively on the mechanism induced by temperature shocks we do not consider any type of labor market or financial frictions.
} 
where $\delta_{K}$ is the depreciation rate of capital. $G(\cdot)$, the function transforming investment into new capital, features convex adjustment costs as in Jermann (1998):

$$
G:=G\left(\frac{I_{t}}{K_{t}}\right)=\frac{\alpha_{1}}{1-\frac{1}{\tau}}\left(\frac{I_{t}}{K_{t}}\right)^{1-\frac{1}{\tau}}+\alpha_{2} .
$$

The firm chooses capital, labor, and investment to maximize firm value:

$$
V_{t}=\max _{L_{t}, I_{t}, K_{t+1}} \mathbb{E}_{t}\left[\sum_{s=0}^{\infty} M_{t, t+s} D_{t+s}\right] .
$$

The net profit (i.e., the dividend) of the firm at any point in time $t, D_{t}$, is given by output minus investment and labor costs:

$$
D_{t}=Y_{t}-I_{t}-W_{t} L_{t}
$$

The firm's investment decision leads to

$$
q_{t}=\frac{1}{G^{\prime}\left(\frac{I_{t}}{K_{t}}\right)},
$$

where $q_{t}$ defines the marginal value of standardized capital which is, in turn, equal to the marginal rate of transformation between new capital and consumption. The firm chooses capital such that

$$
1=\mathbb{E}_{t}\left[M_{t, t+1} \frac{1}{q_{t}}\left(\frac{\alpha Y_{t+1}-I_{t+1}}{K_{t+1}}+q_{t+1}\left(G_{t+1}+1-\delta_{K}\right)\right)\right] .
$$

This can be rewritten as

$$
1=\mathbb{E}_{t}\left[M_{t, t+1} R_{t+1}\right],
$$

where

$$
R_{t+1}=\frac{d_{t+1}+q_{t+1}}{q_{t}}
$$

and

$$
d_{t+1}=\alpha \frac{Y_{t+1}}{K_{t+1}}-\frac{I_{t+1}}{K_{t+1}}+q_{t+1} G_{t+1}-\delta_{K} q_{t+1}
$$

Eq. (3) defines the asset pricing restriction for the gross equity return $R_{t+1}$ which is defined as the return per unit of (normalized) capital.

\subsection{Productivity and temperature dynamics}

The productivity growth rate, $\Delta a_{t+1} \equiv \log \left(A_{t+1} / A_{t}\right)$, in our economy exhibits the following dynamics

$$
\begin{aligned}
\Delta a_{t+1} & =\mu_{a}+x_{t}+x_{t+1}^{z}+\sigma_{a} \epsilon_{a, t+1} \\
x_{t} & =\rho_{x} x_{t-1}+\sigma_{x} \epsilon_{x, t} \\
x_{t+1}^{z} & =\rho_{x}^{z} x_{t}^{z}+\tau_{z} \sigma_{z} \epsilon_{z, t+1} \\
z_{t+1} & =\mu_{z}+\rho_{z}\left(z_{t}-\mu_{z}\right)+\sigma_{z} \epsilon_{z, t+1} .
\end{aligned}
$$

where the shocks $\epsilon_{a, t+1}, \epsilon_{x, t+1}$, and $\epsilon_{z, t+1}$ are independent of each other and are each distributed i.i.d. standard normally. The unconditional expected growth rate of productivity is $\mu_{a}$. The parameter $\mu_{z}$ captures the long-run U.S. average temperature level. In this economy, short-run productivity shocks are induced by $\epsilon_{a, t}$, whereas $\epsilon_{x, t}$ and $\epsilon_{z, t}$ indicate long-run shocks affecting the persistent stochastic components in productivity growth $x_{t}$ and $x_{t}^{z}{ }^{10}$ The persistence of long-run macro and temperature productivity shocks is measured by $\rho_{x}$ and $\rho_{x}^{z}$, respectively. We specify two distinct long-run components for macro and temperature shocks in order to disentangle the timing of those innovations. In contrast to long-run macro shocks, unexpected temperature increases have a contemporaneous impact on TFP growth as suggested by our empirical analysis and existing evidence (see Colacito et al., 2016). ${ }^{11}$ The shock term $\tau_{z} \sigma_{z} \epsilon_{z, t+1}$ is the key innovation in our model relative to standard production-based approaches, since it represents the impact of temperature changes on TFP. $\sigma_{z} \epsilon_{z, t+1}$ is the unpredictable part of the change in temperature $z$. The parameter $\tau_{z}$ in the dynamics for $x^{z}$ in (4) captures the direction and

\footnotetext{
10 Segal et al. (2015) use a similar approach to examine the effects of uncertainty on long-run consumption growth. In their setting, uncertainty is divided into good and bad volatility components which are found to have opposite impact on aggregate growth and asset prices.

11 Lagged temperature does not affect simulated moments and welfare costs significantly. However, the response of macroeconomic variables (in particular labor productivity) on impact is different. Results for this alternative specification of the aggregate productivity growth rate are available upon request.
} 
the intensity with which unpredictable temperature shocks impact long-run productivity growth. ${ }^{12}$ Based on the empirical analysis presented in Section 2, we impose $\tau_{z}<0$ when we study the quantitative implications of the model, i.e., temperature shocks have a negative impact on long-run expected productivity growth. Whereas temperature has an impact on TFP growth, we assume that there is no effect in the opposite direction, i.e., productivity shocks do not affect temperature.

\subsection{Labor market}

Firms' optimal labor allocation condition implies that the wages paid by the firm must equal the marginal product of labor:

$$
W_{t}=(1-\alpha) \frac{Y_{t}}{L_{t}}
$$

The household's optimal labor allocation leads to

$$
W_{t}=\frac{1-v}{v}\left(\frac{C_{t}}{1-L_{t}}\right)
$$

i.e., the marginal rate of substitution between consumption and leisure corresponds to the wage rate that the household receives.

\subsection{Market clearing}

The output produced by the firm can be either consumed by the household or invested by the firm. Therefore, goods market clearing implies that

$$
Y_{t}=C_{t}+I_{t}
$$

\section{Quantitative analysis}

In this section, we present our quantitative results. We calibrate our model according to standard values in the longrun risk literature and statistics on U.S temperature. This allows the model to reproduce moments that are close to their empirical counterparts. The model-implied impulse response functions confirm the negative impact of temperature shocks on macro variables observed in the data. Further, we quantify the welfare costs of temperature risk and estimate the impact of a one-standard deviation shock on aggregate output growth over a 50-year horizon. Our results lie in the range of existing estimates. Finally, we introduce stochastic adaptation in our model and show that investment in adaptation can reduce welfare costs considerably.

\subsection{Calibration}

To be consistent with the frequency of the data used in the empirical analysis in Section 2, we calibrate our benchmark model at an annual frequency. Overall, the proposed production economy requires us to specify sixteen parameters: four for preferences, three relating to the final goods production technology, four describing the TFP process, and five for the dynamics of the U.S. temperature. ${ }^{13}$

We begin with the standard parameters. Most of the parameters are set in accordance with the long-run risk literature and are chosen to match the main dynamics of U.S. macroeconomic and asset pricing data. Precisely, as in Croce (2014), we set the coefficient of relative risk aversion, $\gamma$ and the elasticity of intertemporal substitution (IES), $\psi$, to values of 10 and 2 , respectively (i.e., the representative agent has preference for the early resolution of uncertainty, since $\gamma>\psi^{-1}$ ). In line with Bansal and Ochoa (2011), the annualized subjective discount factor, $\beta$, is fixed at 0.988 . The consumption share in the utility bundle $\tilde{C}$ is chosen such that the steady-state supply of labor is one third of the total time endowment of the household. Given the other parameters, this is achieved by setting $v=0.3416$.

On the final production side, we set the capital share $\alpha$ in the production technology equal to 0.345 as in Croce (2014). Regarding the adjustment cost parameters, $\tau$ is set to 0.7 as in Kung and Schmid (2015). The constants $\alpha_{1}$ and $\alpha_{2}$ are chosen such that there are no adjustment costs in the deterministic steady state. The depreciation rate of capital $\delta_{K}$ is set to 0.06 as in Croce (2014). The parameter $\mu_{a}$ is set to a value of 0.013 so that the average annual TFP growth rate is $1.3 \%$, as indicated by the U.S. data. The volatility of the short-run shock, $\sigma_{a}$, is calibrated to match the annual volatility of output growth

\footnotetext{
12 Cai et al. (2015) also study the effects of climate risk when TFP growth is subject to both short and long-run macroeconomic shocks. Different from us, they make use of an IAM framework and assume that temperature negatively affects the level of TFP. Moreover, they consider a frictionless economy and model population growth over time.

13 The calibration presented here is meant as a benchmark. We have found that our main results are robust to reasonable variations around this benchmark.
} 
Table 1

Benchmark calibration.

\begin{tabular}{|c|c|c|c|}
\hline Parameter & Description & Source & Value \\
\hline \multicolumn{4}{|l|}{ Preferences } \\
\hline$\beta$ & Subjective time discount factor & 2 & 0.988 \\
\hline$\psi$ & Elasticity of intertemporal substitution & 1 & 2 \\
\hline$\gamma$ & Relative risk aversion & 1 & 10 \\
\hline$v$ & Consumption share in utility bundle & 4 & 0.3416 \\
\hline \multicolumn{4}{|c|}{ Production and investment parameters } \\
\hline$\alpha$ & Capital share in final good production & 1 & 0.345 \\
\hline$\delta_{K}$ & Depreciation rate of physical capital & 1 & 0.06 \\
\hline$\tau$ & Capital adjustment costs elasticity & 3 & 0.7 \\
\hline \multicolumn{4}{|c|}{ Capilal dajustment costs eldsticity } \\
\hline$\mu_{a}$ & Long-run mean of TFP growth & 4 & 0.013 \\
\hline$\sigma_{a}$ & Volatility of short-run shocks to TFP growth & 4 & 0.02525 \\
\hline$\rho_{x}$ & Long-run macro TFP shock persistence & 4 & 0.92 \\
\hline$\sigma_{x}$ & Volatility of long-run shocks to TFP & 4 & $0.13^{*} \sigma_{a}$ \\
\hline \multicolumn{4}{|c|}{ Temperature } \\
\hline$\mu_{z}$ & Long-run mean of U.S. temperature & 4 & $52.43^{\circ} \mathrm{F}$ \\
\hline$\tau_{z}$ & Impact of temperature innovations on TFP growth & 4 & -0.00275 \\
\hline$\rho_{x}^{z}$ & Long-run temperature TFP shock persistence & 4 & 0.85 \\
\hline$\rho_{z}$ & Temperature persistence parameter & 4 & 0.5 \\
\hline$\sigma_{z}$ & Volatility of shocks to U.S. temperature & 4 & 0.825 \\
\hline
\end{tabular}

Notes: This table reports the parameters used in the annual calibration of the model described in Section 3. Parameter sources: $1=$ Croce (2014), $2=$ Bansal and Ochoa (2011), 3 = Kung and Schmid (2015), 4 = own calibration.

observed in the macroeconomic data (i.e., around 2.3\%). We calibrate then the parameters of the long-run productivity risk process, $x_{t}$, according to empirical estimates and impose $\rho_{x}=0.92$ and $\sigma_{x}=0.13 \sigma_{a} \cdot{ }^{14}$

We next turn to the "non-standard" parameters (i.e., temperature-related parameters). The persistence of the innovations in the long-run temperature risk component is chosen to let the model reproduce the persistent effect of temperature shocks on TFP growth observed in the data. To this end, we set $\rho_{x}^{z}=0.85$. Changes in $\rho_{z}^{x}$ do not (significantly) affect the (i) unconditional correlation between temperature and TFP growth, (ii) unconditional correlation between temperature and GDP growth significantly, and (iii) autocorrelation of TFP growth. The parameter $\tau_{z}$, measuring the impact of temperature shocks on TFP growth, is calibrated to a value of -0.00275 , which implies in our model that productivity growth declines by around $0.2 \mathrm{pp}$ after an unexpected one-standard deviation increase in temperature. Note that this choice also helps us to obtain an unconditional correlation between TFP growth and between temperature that is close to the data. In the alternative scenario of higher temperature risk that will also be discussed, a value of -0.00375 is assumed. This choice corresponds to a decline of TFP growth by around $0.3 \mathrm{pp}$ and represents the lower bound of the $90 \%$ confidence bands of the bivariate VAR of temperature and TFP growth presented in Fig. 1. The other parameters regarding temperature dynamics are set to match the U.S. temperature statistics observed in the data over the period 1950-2015. In particular, we set $\mu_{z}=52.53$ (degrees Fahrenheit) and $\sigma_{z}=0.825$ to match the long-term mean and volatility of U.S. temperature, respectively. Finally, as suggested by empirical estimates, we set the autoregressive coefficient of U.S. temperature $\rho_{z}$ equal to $0.5 .{ }^{15}$

\subsection{Temperature risk: macro-quantities and asset prices}

The main results produced by our benchmark calibration (BC) are reported in Table 2, specification [1]. In line with standard long-run risk models, our framework produces a relatively high equity premium of $2.63 \%$ and a relatively low riskfree rate of $1.23 \%$, close to what is observed on the major capital markets around the world. If we compare these results with specification [2], i.e., a model without temperature effects, we observe that long-run temperature risk is responsible for a $0.27 \mathrm{pp}$ increase in the total equity premium.

14 We estimate the following state-space model:

$$
\begin{aligned}
\Delta a_{t} & =0.013+x_{t-1}+\underbrace{\sigma_{a, t}}_{0.017_{[0.0000]}^{* * *}} \cdot \epsilon_{a, t} \\
x_{t} & =\underbrace{\rho_{x}}_{0.92_{[0.0000]}^{* *}} \cdot x_{t-1}+\underbrace{\sigma_{x, t}}_{0.0021_{[0.000]}^{* *}} \cdot \epsilon_{x, t}
\end{aligned}
$$

where 0.013 corresponds to the estimated U.S. long-run mean of aggregated productivity, $\rho_{x}$ is the estimated persistence parameter of the long-run productivity component, $\sigma_{a, t}$ and $\sigma_{x, t}$ are the estimated volatilities of the short- and long-run TFP shock, and $\epsilon_{a, t}$ and $\epsilon_{x, t}$ are independent and identically distributed standard normal shocks. Estimates are obtained using the Newton-Raphson optimization procedure with Marquardt step. Huber-White standard errors are employed in order to account for heteroskedasticity. P-values are reported in square brackets. ${ }^{* * *}$ indicates significance at $0.1 \%$ level.

${ }^{15}$ For space considerations, standard estimates are not reported but are available from the authors upon request. 
Table 2

Model versus data: macroeconomic quantities and asset prices.

\begin{tabular}{|c|c|c|c|c|}
\hline Variable & Data & $\mathrm{BC}$ & $\tau_{z}=0$ & $\tau_{z}=-0.00375$ \\
\hline & & [1] & {$[2]$} & [3] \\
\hline \multicolumn{5}{|l|}{ Macro quantities } \\
\hline $\mathbb{E}(\Delta a)$ & 1.30 & 1.33 & 1.33 & 1.33 \\
\hline$A C 1(\Delta a)$ & 0.07 & 0.07 & 0.05 & 0.08 \\
\hline$\sigma(\Delta y)$ & 2.29 & 2.39 & 2.37 & 2.41 \\
\hline$\sigma(\Delta l p)$ & 2.24 & 2.04 & 2.02 & 2.06 \\
\hline$\sigma(\Delta c) / \sigma(\Delta y)$ & 0.79 & 0.82 & 0.82 & 0.82 \\
\hline$\sigma(\Delta i) / \sigma(\Delta y)$ & 4.13 & 1.81 & 1.81 & 1.81 \\
\hline$\sigma(\Delta w) / \sigma(\Delta y)$ & 0.91 & 0.85 & 0.85 & 0.85 \\
\hline$\sigma(\Delta l) / \sigma(\Delta y)$ & 1.12 & 0.32 & 0.32 & 0.32 \\
\hline$\rho(\Delta c, \Delta y)$ & 0.84 & 0.88 & 0.88 & 0.88 \\
\hline$\rho(\Delta c, \Delta i)$ & 0.75 & 0.56 & 0.56 & 0.56 \\
\hline$\rho(\Delta w, \Delta y)$ & 0.30 & 0.95 & 0.95 & 0.95 \\
\hline$\rho(\Delta l, \Delta y)$ & 0.80 & 0.59 & 0.59 & 0.58 \\
\hline$\rho(\Delta l p, \Delta y)$ & 0.99 & 0.95 & 0.95 & 0.95 \\
\hline$\rho(\Delta i, \Delta l)$ & 0.81 & 0.89 & 0.89 & 0.89 \\
\hline \multicolumn{5}{|l|}{ Temprature } \\
\hline $\mathbb{E}(z)$ & 52.43 & 52.43 & 52.43 & 52.43 \\
\hline$\sigma(z)$ & 0.94 & 0.94 & 0.94 & 0.94 \\
\hline$\rho(z, \Delta a)$ & -0.15 & -0.12 & 0.00 & -0.16 \\
\hline$\rho(z, \Delta y)$ & -0.24 & -0.12 & 0.00 & -0.16 \\
\hline \multicolumn{5}{|l|}{ Asset prices } \\
\hline $\mathbb{E}\left(R^{f}\right)$ & 1.23 & 1.23 & 1.28 & 1.18 \\
\hline$\sigma\left(R^{f}\right)$ & 2.16 & 0.70 & 0.68 & 0.71 \\
\hline $\mathbb{E}\left[R^{m}-R^{f}\right]$ & 4.30 & 2.63 & 2.36 & 2.87 \\
\hline$\sigma\left(\mathbb{E}\left[R^{m}-R^{f}\right]\right)$ & 16.80 & 5.45 & 5.24 & 5.63 \\
\hline$\rho\left(z, R^{m}\right)$ & -0.07 & -0.25 & 0.00 & -0.33 \\
\hline
\end{tabular}

Notes: This table reports the main moments for the benchmark calibration (specification [1]) and two other model specifications. In model [2], we assume that temperature does not affect long-run productivity growth, i.e., $\tau_{z}=0$ in Eq. (4). In model [3], by imposing $\tau_{z}=-0.00375$, temperature shocks are assumed to have a larger impact on productivity growth. The aggregate market return is levered as in Croce (2014). Models' entries are obtained from repetitions of small-sample simulations (i.e., averages over 1000 simulations of 100 years). $\mathbb{E}[\cdot], \sigma(\cdot), \rho(\cdot, \cdot)$, and $A C 1(\cdot)$ denote mean, volatility, correlation, and first-order autocorrelation, respectively. Means and volatilities are expressed in percentage points. Data on U.S. temperature and macro-aggregates are from the NOAA National Centers for Environmental information and Bureau of Economic Analysis, respectively. Data are annual and run from 1950 to 2015. Additional details on data are provided in Appendix A.

Equity volatility is also slightly higher in the model with temperature effects (i.e., $+0.2 \mathrm{pp}$ ). In line with the impulse responses presented in Fig. 3, we observe a negative correlation between the equity market return and the level of temperature (i.e, -0.25). The reason for this is that unexpected increases in temperature negatively affect firms' productivity and, hence, their return on capital. In the data, the negative correlation is less pronounced compared to our model. In general, the inclusion of temperature risk leads to more pronounced aggregate productivity shifts and, consequently, to relatively worse long-run growth prospects. This additional effect is priced by the agent since she has a preference for early resolution of uncertainty.

When the adverse impact of temperature shocks on TFP growth becomes more severe, as presented in specification [3] with $\tau_{z}=-0.00375$, the equity risk premium increases even further to a value of $2.87 \%$. Of course, this implies also a stronger negative co-movement between temperature and TFP growth as well as between temperature and equity market returns.

The negative effects of temperature increases on the macroeconomy are reflected by a negative correlation between the level of temperature and both TFP and output growth, each at -0.12 . The moments of macroeconomic quantities are robust to the inclusion of temperature effects as they do not induce excessive volatility into the business cycle.

\subsection{Inspecting the mechanism}

Unexpected temperature increases are transmitted to the business cycles via their negative effect on TFP growth. More specifically, they constitute a negative shock to the long-run risk component of productivity growth. Fig. 4 presents the responses of selected macro quantities to a temperature shock. In contrast to long-run macro shocks, an unexpected temperature increase has a contemporaneous effect on TFP growth of about $-0.22 \mathrm{pp}$ on impact. This causes consumption growth to fall immediately after the shock by about $0.08 \mathrm{pp}$ (Panel B). ${ }^{16}$ Lower productivity also translates into a strong decline of investment by $-0.5 \mathrm{pp}$. As a result, total output growth declines by more than $0.2 \mathrm{pp}$ (Panel C).

\footnotetext{
${ }^{16}$ With lagged temperature effects, consumption would increase on impact because of the dominance of the substitution effect. Lower productivity reduces the opportunity costs of consumption and leisure.
} 

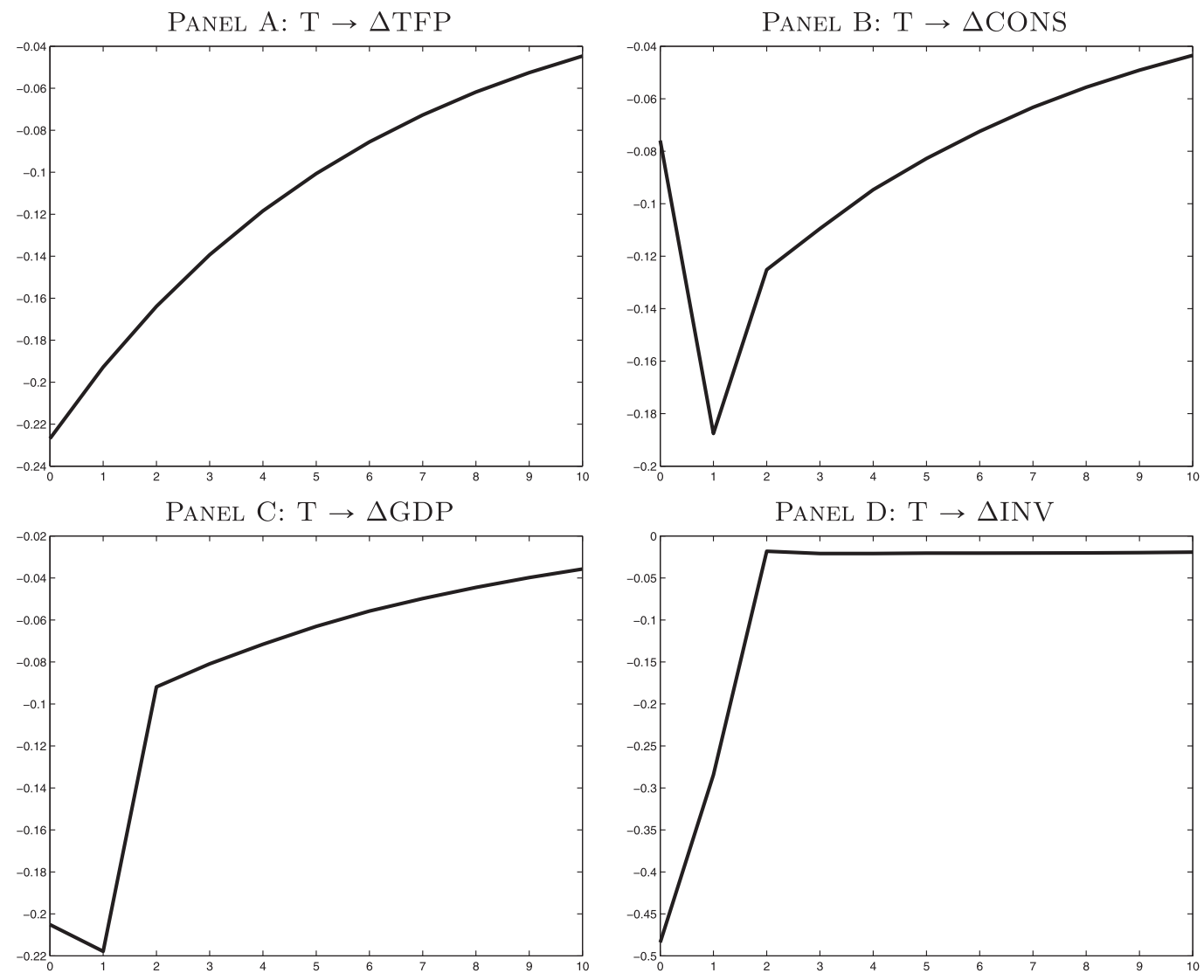

PANEL E: $\mathrm{T} \rightarrow \Delta \mathrm{L}$
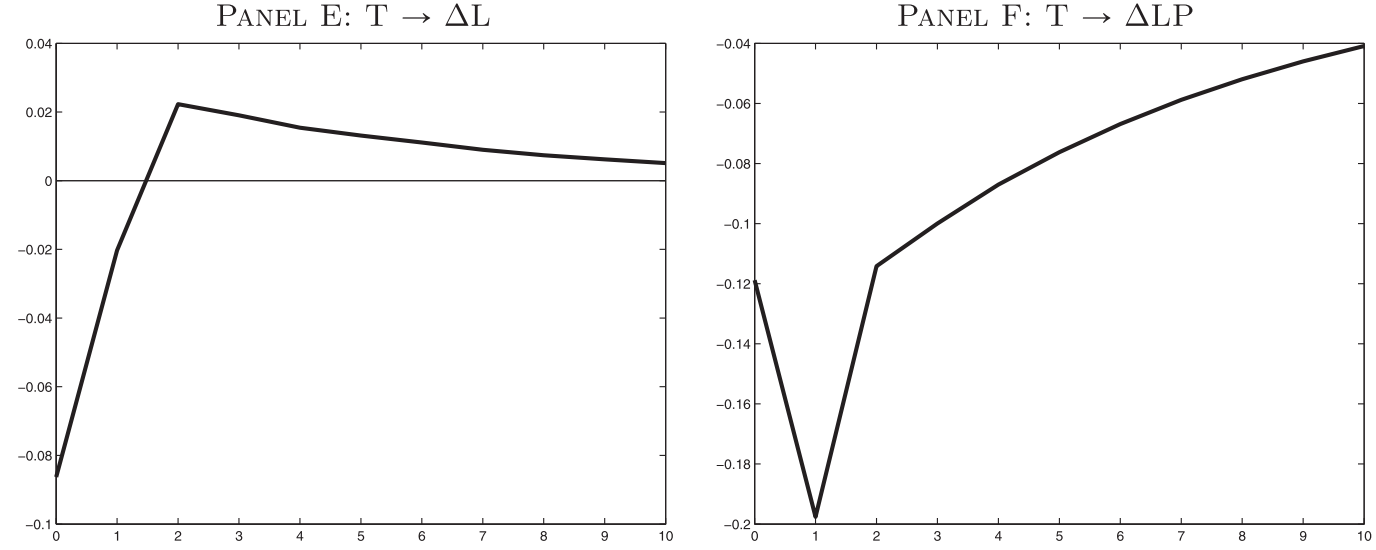

Fig. 4. Responses of macro quantities to a temperature shock.

Notes: This figure reports impulse responses (expressed as deviation from the steady state in percentage points) for a length of 10 years of TFP growth, $\Delta \mathrm{TFP}$, consumption growth, $\Delta \mathrm{CONS}$, output growth, $\Delta \mathrm{GDP}$, investment growth, $\Delta \mathrm{INV}$, labor growth, $\Delta \mathrm{L}$, and labor productivity growth, $\Delta \mathrm{LP}$, with respect to a temperature shock, $T$. All the parameters are calibrated to the values reported in Table 1 .

The key advantage of our model featuring a production sector is that it allows us to analyze the impact of temperature shocks on labor-related quantities. While labor growth falls on impact, it becomes positive afterwards. According to the income effect, consumption of leisure decreases as the agent feels poorer, i.e., she works more. Labor productivity growth declines both on impact and in the future (Panel F). In the first period of the shock, labor growth decreases less than output growth. Later on, the positive income effect on labor exacerbates the negative effects of output losses. The immediate decrease of labor productivity in response to a positive temperature shock is in line with existing empirical evidence (see, among others, Deryugina and Hsiang, 2014; Park, 2016). 


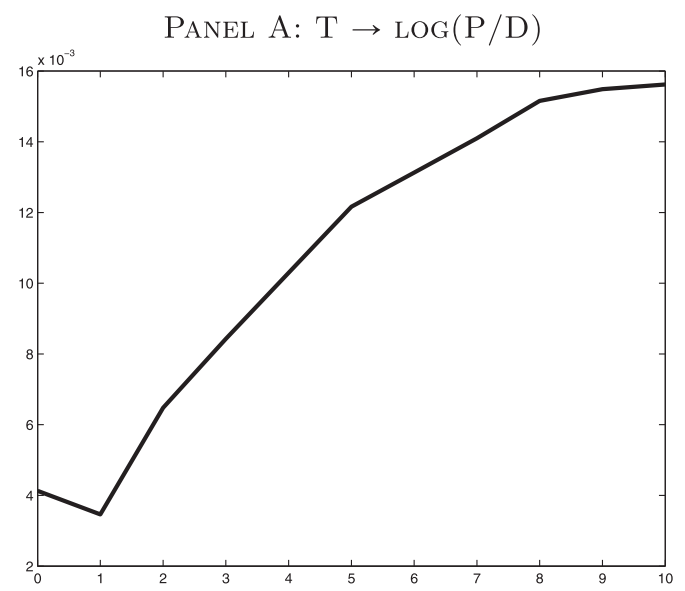

PANEL B: $\mathrm{T} \rightarrow \mathrm{RF}$

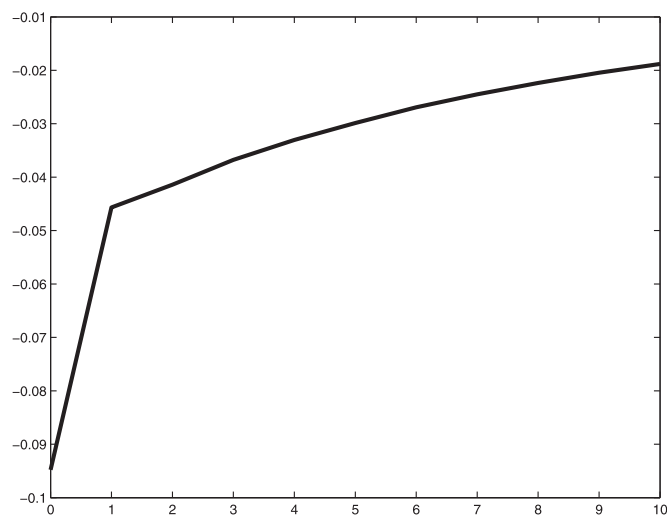

Fig. 5. Responses of financial variables to a temperature shock.

Notes: This figure reports impulse responses (expressed as deviation from the steady state in percentage points) for a length of 10 years of log of price dividend ration, $\operatorname{LOG}(\mathrm{P} / \mathrm{D})$ and risk-free rate, RF, with respect to a temperature shock, $T$. All the parameters are calibrated to the values reported in Table 1.

The model's responses of macro quantities are both qualitatively and quantitatively in line with our empirical VAR estimations. This speaks in favor of modeling temperature shocks within a production economy with endogenous investment and labor decisions.

Temperature shocks not only affect the real economy but also financial markets, as depicted in Fig. 5. Lower productivity decreases the firm's profits and, hence, dividends. As aggregate investment is depressed, the price of capital depreciates and negatively impacts equity prices. Since dividends experience a stronger contraction than equity prices in our model, the price dividend-ratio increases following the shock. These effects are line with our empirical estimations (Fig. 3, Panel A). Lower dividends lead then to a drop in equity prices. This confirms most recent empirical evidence suggesting that temperature shocks have a negative impact on asset prices (see Bansal et al., 2016; Balvers et al., 2017). As a result, the agent demands more of the risk-free asset, and the increased demand leads to a decline in the risk-free rate (Panel B), which is also in line with our empirical findings (Fig. 3, Panel B).

Taken together, our findings suggest that climate change in the sense of positive temperature shocks is an important factor for the long-run evolution of key macroeconomic quantities and financial variables. Its impact is uniformly negative with respect to a wide variety of measures for economic activity and real asset valuations. ${ }^{17}$

\subsection{Welfare costs}

To measure the economic costs of temperature shocks, we compute welfare losses that arise due to temperature risk. The losses are calculated in a fashion similar to Bansal and Ochoa (2011). Specifically, we compare the agent's utility in an economy with temperature risk to her utility in an economy without temperature risk. Formally, welfare costs $\Delta$ are implicitly defined by:

$$
\mathbb{E}\left[U_{0}((1+\Delta) \tilde{C})\right]=\mathbb{E}\left[U_{0}\left(\tilde{C}^{*}\right)\right],
$$

where $\tilde{C}=\left\{\tilde{C}_{t}\right\}_{t=0}^{\infty}$ and $\tilde{C}^{*}=\left\{\tilde{C}_{t}^{*}\right\}_{t=0}^{\infty}$ denote the optimal consumption paths with and without temperature risk, respectively.

Table 3 displays welfare costs for temperature effects in the benchmark economy and for the case with higher adverse effects of temperature. Additionally, costs are calculated for two values of the intertemporal elasticity of substitution. We do this to show that our results are qualitatively robust to whether the substitution ( $\psi=2$, as in the benchmark case) or the income $(\psi=0.9)$ effect dominates.

In our benchmark calibration, welfare costs amount to $18.4 \%$ of per capita composite consumption which is represented by the bundle consisting of consumption and leisure. This means that the composite consumption of an agent living in an economy with temperature risk needs to be increased by almost a fifth in every state and at every point in time to give the agent the same utility as in an economy without temperature risk. The costs of temperature shocks are sizable since they have a large and persistent impact on productivity and subsequently on the other macroeconomic and financial variables.

In the case where TFP growth is more sensitive to temperature shocks ( $\tau_{z}=-0.00375$ ), welfare costs increase to $36.8 \%$. As shown in Fig. 6, it turns out that welfare costs increase exponentially in the absolute value of $\tau_{z}$. For the largest impact of temperate on TFP shown in the picture $\left(\tau_{z}=-0.006\right)$, welfare costs amount to roughly $120 \%$ of composite consumption, i.e.,

\footnotetext{
17 An alternative way to study the equilibrium response of macroeconomic variables is to estimate the VAR on model generated data. We report in Appendix B the impulse response functions obtained from a long sample simulation (see Fig. B.3). These model-implied responses are very close to the theoretical ones and, more importantly, close to the empirical VAR predictions discussed in Section 2.
} 
Table 3

Welfare costs of temperature shocks.

\begin{tabular}{ccc}
\hline & BC & Temp-effects $\uparrow$ \\
$\psi$ & $\left(\tau_{z}=-0.00275\right)$ & $\left(\tau_{z}=-0.00375\right)$ \\
{$[2]$}
\end{tabular}

Notes: This table reports the welfare costs of temperature risk for two different IES values. Welfare costs are defined as the percentage increase $\Delta>0$ in composite consumption $(\tilde{C})$ that the household should receive in every state and at every point in time in order to be indifferent between living in an economy with full risk exposure (i.e., $\sigma_{z}, \sigma_{a}, \sigma_{x}>0$ ) and an economy where temperature risk is eliminated (i.e., $\tau_{z}=0$ ). Specification [1] refers to the benchmark calibration (i.e., $\tau_{z}=-0.00275$ ) while specification [2] accounts for higher temperature effects (i.e., $\tau_{z}=-0.00375$ ).

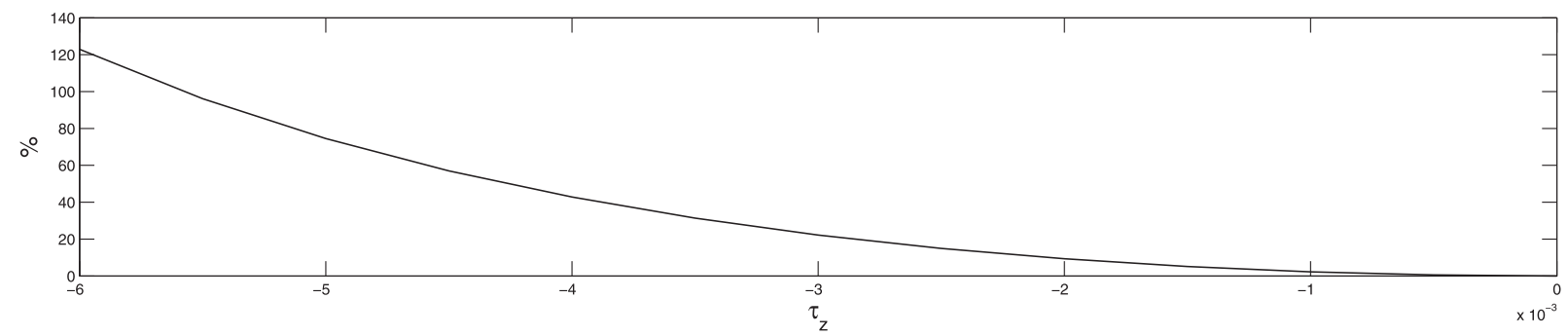

Fig. 6. Welfare costs.

Notes: This figure reports welfare costs for different values of $\tau_{z}$. Welfare costs are computed as in Eq. (6). All the remaining parameters are set to the values shown in Table 1.

compared to the case without temperature risk the representative household would need more than twice the composite consumption to achieve the same utility level.

We also analyze welfare costs for a lower value $\psi=0.9$ of the IES. This case is interesting in itself since macroeconomists and finance researchers do not fully agree whether the IES is indeed greater than one or not. In our model, a lower IES changes the results quantitatively but not qualitatively. For the benchmark calibration the welfare loss is three times as high as in the case with lower IES. Welfare costs are increasing in the IES, since a higher IES implicitly makes the agent more patient, i.e., future consumption has a higher weight in the value function. Therefore, temperature shocks as a source of long-run macroeconomic risk is much costlier for the agent.

Compared to our study, welfare costs of temperature risk in the endowment economy of Bansal and Ochoa (2011) are found to be smaller and amount to only $0.78 \%$. However, the two frameworks cannot be directly compared as introducing temperature shocks into a production economy yields significantly different consumption dynamics. This heterogeneity in consumption dynamics is due to the fact that our framework endogenizes movements of capital and investment which, in turn, works as an amplification mechanism.

In this regard, the presence of investment adjustment costs plays a crucial role. Barlevy (2004) shows that welfare costs produced by the volatility of productivity are amplified in economies with capital adjustment costs. Similarly, Croce (2006) finds that, given otherwise identical calibrations, welfare costs in a production economy are higher than those observed in an endowment economy since long-run risk in productivity results in a higher level of long-run uncertainty in the (now endogenous) growth rate of consumption. The economic mechanism behind the impact of adjustment costs works as follows. When it is costly to change the capital stock, the agent can no longer as easily use investment to reduce the exposure of her consumption process to long-run risk. Adjustment costs generate a negative income effect that lowers both the level and the growth rate of consumption. The amplification through endogenous investment subject to adjustment costs is therefore the main reason why our results differ significantly from the findings presented by Bansal and Ochoa (2011).

To better put our numbers in perspective, temperature-induced welfare losses should be compared to other significant risks modeled in a production framework, e.g., oil price shocks as analyzed by Hitzemann and Yaron (2016). They find wealth losses of about $2.5 \%$, which are significantly smaller than the $18.4 \%$ we obtain for our baseline calibration. Obviously this is only a rough comparison, but it nevertheless indicates that temperature risk is a factor that significantly affects an agent's welfare. $^{18}$

Overall, our analysis suggests that the welfare costs of rising temperatures are non-negligible. We acknowledge that the reported welfare costs are based on today's estimated impact coefficients and do not take into account potential benefits

\footnotetext{
18 There also cannot be a one-to-one mapping between the welfare costs of temperature risk reported in our analysis and the economic costs of rising temperatures computed by Golosov etal. (2014) and Cai etal. (2015). As we focus on temperature risk instead of trend increases in temperature, welfare costs are defined as extra consumption needed to compensate the agent for climate risk (i.e., temperature shocks). Golosov et al. (2014) and Cai et al. (2015), instead, compute economic costs in terms of damage to the level of GDP due to trend increases in global temperature.
} 
Table 4

Model versus data: macroeconomic quantities and asset prices.

\begin{tabular}{|c|c|c|c|c|}
\hline Variable & Data & $\mathrm{BC}$ & $\begin{array}{c}\text { Temp vol } \uparrow \\
\left(1.2^{*} \sigma_{z}\right)\end{array}$ & $\begin{array}{c}\mathrm{SV} \\
\left(\sigma_{v}>0\right)\end{array}$ \\
\hline & & [1] & [2] & [3] \\
\hline \multicolumn{5}{|l|}{ Macro quantities } \\
\hline $\mathbb{E}(\Delta a)$ & 1.30 & 1.33 & 1.33 & 1.32 \\
\hline $\operatorname{AC1}(\Delta a)$ & 0.07 & 0.07 & 0.08 & 0.07 \\
\hline$\sigma(\Delta y)$ & 2.29 & 2.39 & 2.40 & 2.40 \\
\hline$\sigma(\Delta l p)$ & 2.24 & 2.04 & 2.05 & 2.05 \\
\hline$\sigma(\Delta c) / \sigma(\Delta y)$ & 0.79 & 0.82 & 0.82 & 0.82 \\
\hline$\sigma(\Delta i) / \sigma(\Delta y)$ & 4.13 & 1.81 & 1.81 & 1.81 \\
\hline$\sigma(\Delta w) / \sigma(\Delta y)$ & 0.91 & 0.85 & 0.85 & 0.85 \\
\hline$\sigma(\Delta l) / \sigma(\Delta y)$ & 1.12 & 0.32 & 0.32 & 0.32 \\
\hline$\rho(\Delta c, \Delta y)$ & 0.84 & 0.88 & 0.88 & 0.88 \\
\hline$\rho(\Delta c, \Delta i)$ & 0.75 & 0.56 & 0.56 & 0.56 \\
\hline$\rho(\Delta w, \Delta y)$ & 0.30 & 0.95 & 0.95 & 0.95 \\
\hline$\rho(\Delta l, \Delta y)$ & 0.80 & 0.59 & 0.59 & 0.59 \\
\hline$\rho(\Delta l p, \Delta y)$ & 0.99 & 0.95 & 0.95 & 0.95 \\
\hline$\rho(\Delta i, \Delta l)$ & 0.81 & 0.89 & 0.89 & 0.89 \\
\hline \multicolumn{5}{|l|}{ Temperature } \\
\hline $\mathbb{E}(z)$ & 52.43 & 52.43 & 52.43 & 52.43 \\
\hline$\sigma(z)$ & 0.94 & 0.94 & 1.13 & 0.94 \\
\hline$\rho(z, \Delta a)$ & -0.15 & -0.12 & -0.14 & -0.11 \\
\hline$\rho(z, \Delta y)$ & -0.24 & -0.12 & -0.14 & -0.11 \\
\hline \multicolumn{5}{|l|}{ Asset prices } \\
\hline $\mathbb{E}\left(R^{f}\right)$ & 1.23 & 1.23 & 1.20 & 1.23 \\
\hline$\sigma\left(R^{f}\right)$ & 2.16 & 0.70 & 0.70 & 0.70 \\
\hline $\mathbb{E}\left[R^{m}-R^{f}\right]$ & 4.30 & 2.63 & 2.75 & 2.62 \\
\hline$\sigma\left(\mathbb{E}\left[R^{m}-R^{f}\right]\right)$ & 16.80 & 5.45 & 5.54 & 5.45 \\
\hline$\rho\left(z, R^{m}\right)$ & -0.07 & -0.25 & -0.29 & -0.24 \\
\hline
\end{tabular}

Notes: This table reports the main moments for the benchmark calibration (specification [1]) and two other model specifications. Specification [2] simply assumes a higher volatility of temperature. Specification [3] introduces time-varying volatility of temperature as defined in Eq. (7). The aggregate market return is levered as in Croce (2014). The entries for the models are obtained from repetitions of small-sample simulations (i.e., averages over 1000 simulations of 100 years). $\mathbb{E}[\cdot], \sigma(\cdot), \rho(\cdot, \cdot)$, and $A C 1(\cdot)$ denote mean, volatility, correlation, and first-order autocorrelation, respectively. Means and volatilities are expressed in percentage points. Data on U.S. temperature and macro-aggregates are from the NOAA National Centers for Environmental information and Bureau of Economic Analysis, respectively. Data are annual and run from 1950 to 2015 . Additional details on data are provided in Appendix A.

Table 5

Welfare costs of temp risk: the role of temp-vol changes.

$\left.\begin{array}{lcc}\hline & \text { BC } & \text { Temp-vol } \uparrow \\ \left(1.2 * \sigma_{z}\right) \\ {[2]}\end{array}\right)$

Notes: This table reports the welfare costs of temperature risk for two different IES values. Welfare costs are defined as the percentage increase $\Delta>0$ in composite consumption $(\tilde{C})$ that the household should receive in every state and at every point in time in order to be indifferent between living in an economy with full risk exposure (i.e., $\sigma_{z}, \sigma_{a}, \sigma_{x}>0$ ) and an economy where temperature risk is eliminated (i.e., $\tau_{z}=0$ ). Specification [1] refers to the benchmark calibration. Specification [2] simply assumes a higher volatility of temperature while specification [3] introduces time-varying volatility of temperature as defined in Eq. (7).

from increasing adaptation efforts that are likely to take place in the future (see Park, 2016). In this respect, our numbers should be regarded as an upper bound to the welfare cost of positive temperature shocks.

\subsection{Further inspection of the mechanism}

In this section we perturb the benchmark calibration in order to examine the macroeconomic and welfare effects of changes in the volatility of temperature. The main results from this additional exercise are reported in Tables 4 and 5 . The related economic intuitions are addressed in what follows. ${ }^{19}$

\footnotetext{
${ }^{19}$ Recent macro-finance studies show that real labor market dynamics play an important role in bringing both macro-quantities and asset prices closer to their empirical counterparts (see, among others, Donadelli and Grüning, 2016; Favilukis and Lin, 2016). Motivated by this evidence, we augment our production economy by sticky wages as in Uhlig (2007) to examine whether different degrees of wage stickiness affect macroeconomic quantities, asset prices, and welfare costs in the presence of temperature risk. For brevity's sake, results from this additional analysis are reported in Appendix C.1. In line with other studies, we find that wage rigidities (i) make wages less volatile while increasing the volatility and pro-cyclicality of labor due to insurance
} 


\subsubsection{Time-varying temperature volatility}

In the benchmark model, we assume that the volatility of temperature does not vary over time. However, in the data temperature volatility seems to be increasing over time. For instance, in the sub-sample 1950-1975 the standard deviation of U.S. temperature is equal to 0.55, while it amounts to 0.99 over the period 1976-2015. To account for changes in temperature volatility, $\sigma_{z}$, we perform two simple exercises. First, we simply perturb our benchmark calibration by assuming a higher $\sigma_{z}$. More precisely, we examine the implications on macro-quantities, asset prices, and welfare costs in the case of matching a temperature volatility which is $20 \%$ higher than in the benchmark model. Second, for the sake of completeness, we introduce temperature-based fluctuations in economic uncertainty in the spirit of Croce (2014) and Hitzemann etal. (2016). We therefore consider the following specification for productivity and temperature dynamics:

$$
\begin{aligned}
\Delta a_{t+1} & =\mu_{a}+x_{t}+x_{t+1}^{z}+\sigma_{a} \epsilon_{a, t+1} \\
x_{t} & =\rho_{x} x_{t-1}+\sigma_{x} \epsilon_{x, t} \\
x_{t+1}^{z} & =\rho_{x}^{z} x_{t}^{z}+\tau_{z} e^{v_{t+1}} \sigma_{z} \epsilon_{z, t+1} \\
z_{t+1} & =\mu_{z}+\rho_{z}\left(z_{t}-\mu_{z}\right)+e^{v_{t+1}} \sigma_{z} \epsilon_{z, t+1} \\
v_{t+1} & =\rho_{v} v_{t}+\sigma_{v} \epsilon_{v, t+1},
\end{aligned}
$$

where the process $e^{v_{t}}$ captures time-varying volatility of temperature, and all the shocks are assumed to be mutually independent i.i.d. sequences of standard normally distributed random variables, i.e., $\epsilon_{a, t+1}, \epsilon_{x, t+1}, \epsilon_{z, t+1}, \epsilon_{v, t+1} \sim$ i.i.d. $N(\mathbf{0}, \mathbf{1})$. By means of a standard $\operatorname{GARCH}(1,1)$ estimation, we confirm that the conditional variance of U.S. temperature is time-varying. In addition, the estimates from this time series model suggest $\rho_{v}=0.59$ (i.e., the parameter governing the persistence of temperature conditional volatility) and $\sigma_{v}=0.158$ (i.e., $\sigma_{v}$ is a relatively small percentage of $\sigma_{z}$ ). In line with these estimates, we set the persistence of the stochastic component in temperature volatility, $\rho_{v}$, to 0.6 and its standard deviation, $\sigma_{v}$, to 0.158. For parsimony, volatility shocks are assumed to be orthogonal to all other shocks in the system.

Simulated moments and welfare costs for these two alternative exercises are reported in Tables 4 and 5, respectively. Our results show that a permanently higher temperature volatility (specification [2]) affects mainly asset prices. As suggested by Eq. (4), a variation in $\sigma_{z}$ plays a similar role as a change in the parameter $\tau_{z}$. Consequently, a rise in temperature volatility by $20 \%$ increases temperature risk in the business cycle, resulting in an increase in the equity premium by $0.12 \mathrm{pp}$ and in a strong increase in welfare costs by about 50\% compared to the benchmark model.

Stochastic temperature volatility (specification [3]), instead, does not alter both macro quantities and asset prices. This is due to the fact that data suggest a relatively low persistence and shock size of stochastic volatility for the sample 19502015. Hence, welfare costs of temperature effects are not significantly affected by the introduction of time-varying volatility and remain basically unchanged. Not surprisingly, welfare costs of temperature volatility risk itself amount to only $0.2 \%$ in the benchmark case. Loosely speaking, in our setting stochastic volatility of temperature does not affect lifetime utility in the long-run. Economically, this is due to the fact that equity provides insurance against orthogonal volatility shocks, i.e., agents increase savings and investments into capital in response to volatility risk.

\subsection{Expected losses}

To quantify the long-term effects of temperature increases, we calculate expected losses in output and labor productivity growth for horizons from 1 to 50 years ahead after a temporary positive shock to U.S. temperature. To this end, we compare the cumulative growth in an economy in which temperature negatively affects TFP growth to cumulative growth in an economy without temperature risk. The shock sizes are one and two standard deviations of temperature changes, i.e., $0.825^{\circ} \mathrm{F}$ and $1.65^{\circ} \mathrm{F}$, respectively.

Panels A and B of Table 6 report results for output growth and labor productivity growth. One can see that a single initial temperature shock has a sizable long-run negative impact on these variables, which is clearly due to the fact that a temperature shock induces a long-lasting negative productivity shock. After one year following a one-standard deviation shock, cumulative output and labor productivity growth both decrease by $0.21 \mathrm{pp}$ and $0.12 \mathrm{pp}$, and over a 50 -year horizon, this shock lowers both cumulative output and labor productivity growth by $1.4 \mathrm{pp}$. A U.S. temperature shock of $1.65^{\circ} \mathrm{F}$ exacerbates this effect, leading to a decrease in cumulative output and labor productivity growth by $0.41 \mathrm{pp}$ and $0.24 \mathrm{pp}$ after one year, respectively. Half a century after the shock, the decrease amounts to 2.8pp each. This exercise shows that increases in temperature adversely affect economic activity not only in the short but also in the long run by reducing growth perspectives for output and labor productivity.

The estimates in Table 6 may appear to be small but one should keep in mind that our exercise is based on a single temperature shock only. Since the economy is likely to face a sequence of positive temperature shocks over the next century, our results are intended to simply illustrate the overall effect of a single shock. We abstain from modeling global warming as permanent temperature shocks or as a trend increase in U.S. temperature, nor do we try to model global warming explicitly. $^{20}$

against shocks (see Table C.1), (ii) raise equity risk premium and equity market volatility (see Table C.1), and (iii) have no effects on the welfare costs of temperature risk (see Table C.2).

${ }^{20}$ In the former case, Colacito et al. (2016) estimate that in 100 years U.S. summer and fall temperatures will be on average $3.6^{\circ} \mathrm{F}$ and $2.1^{\circ} \mathrm{F}$ higher, respectively. This climatic development bears the potential to reduce economic growth by up to 1.5 percentage points, according to their projections. The 
Table 6

Long-run effect of a temperature shock.

\begin{tabular}{|c|c|c|c|c|c|}
\hline \multicolumn{6}{|c|}{$\begin{array}{l}\text { Panel A: } \sum_{j=1}^{N} \Delta y_{t+j}-N \cdot \Delta y^{*} \\
\text { Difference in expected output growth after a shock to U.S. temperature }\end{array}$} \\
\hline Shock size & $1 \mathrm{Y}$ & $5 \mathrm{Y}$ & $10 \mathrm{Y}$ & $20 \mathrm{Y}$ & $50 Y$ \\
\hline 1 std. dev. $\sigma_{z}$ & -0.21 & -0.67 & -0.92 & -1.16 & -1.40 \\
\hline 2 std. dev. $\sigma_{z}$ & -0.41 & -1.33 & -1.84 & -2.33 & -2.81 \\
\hline \multicolumn{6}{|c|}{$\begin{array}{l}\text { Panel B: } \sum_{j=1}^{N} \Delta l p_{t+j}-N \cdot \Delta l p^{*} \\
\text { Difference in expected labor productivity growth after a shock to U.S. temperature }\end{array}$} \\
\hline Shock size & $1 \mathrm{Y}$ & $5 Y$ & $10 \mathrm{Y}$ & $20 Y$ & $50 Y$ \\
\hline 1 std. dev. $\sigma_{z}$ & -0.12 & -0.62 & -0.92 & -1.18 & -1.41 \\
\hline 2 std. dev. $\sigma_{z}$ & -0.24 & -1.24 & -1.83 & -2.37 & -2.83 \\
\hline
\end{tabular}

Notes: This table reports the cumulative change in growth over $1,5,10,20$, and 50 years in percentage points after a temporary temperature shock. The cumulative growth in an economy without such a shock is compared to that in an economy with shocks to temperature $z_{t}$. Specifically, we report $\left(\sum_{j=1}^{N} \Delta y_{t+j}\right)-N \cdot \Delta y^{*}$ and $\left(\sum_{j=1}^{N} \Delta l p_{t+j}\right)-N \cdot \Delta l p^{*}$ where $\Delta y_{t+j}\left(\Delta l p_{t+j}\right)$ is the log growth rate of total output (labor productivity), and $\Delta y^{*}\left(\Delta l p^{*}\right)$ is the steady-state growth rate in the economy without a shock (i.e., with $\sigma_{z}=0$ ). For example, the entry -0.67 for a horizon of 5 years in the first row of Panel A means that cumulative growth over these 5 years has been 0.67 percentage points lower than it would have been without the temperature shock. The amount of lost output (Panel A) and labor productivity (Panel B) growth is reported for temperature shocks amounting to one and two standard deviations, i.e., to $0.825^{\circ} \mathrm{F}$ and $1.65^{\circ} \mathrm{F}$, respectively.

\subsection{Temperature shocks, adaptation, and welfare costs}

The literature on adaptation suggests that damages from climate change can be reduced by continued economic development and technological innovation. ${ }^{21}$ One prominent example in this respect is the invention of air conditioning at the beginning of the 20th century. Factories, banks, movie theaters, and many other businesses in the southern states of the U.S. were quick to utilize the new indoor climate control device in production and service. Torrid summer months became bearable for employees and customers, alike. Consequently, the South experienced a significant increase in labor productivity, output, and real wages such that the economic gap relative to the rest of the nation could be considerably reduced (see Arsenault, 1984; Oi, 1996).

Given the evidence that technological progress is likely to affect the overall economic costs of climate risk, we augment our model in order to take into account changing adaptation efforts in the future and the way they affect the parameters governing the size of welfare costs. In our baseline model, temperature increases affect the real economy via three parameters: the sensitivity of TFP growth to a temperature shock on impact, measured by $\tau_{z}$, the persistence of the negative effect on TFP growth, measured by $\rho_{x}^{z}$, and the standard deviation of temperature shocks, $\sigma_{z}$. Actually, our model already features an adaptation mechanism. As suggested by Tol (2002), $\rho_{x}^{z}$ can be interpreted as a parameter governing the speed of adaptation to temperature shocks. A temperature shock does not reduce TFP growth permanently but according to the persistence parameter $\rho_{x}^{z}$. This exogenously imposed adaptation mechanism can be interpreted as the agents' adaptation effort needed to revert back to the old growth path. Therefore, the higher the speed of adaptation the lower $\rho_{x}^{z}$.

To analyze how the speed of adaptation affects welfare costs, we computed the latter for different values of the parameter $\rho_{x}^{z}$, where $\rho_{x}^{z}$ varies from 0 to 0.9 . Results from this sensitivity analysis are plotted in Fig. 7 and suggest that welfare costs increase exponentially in the parameter $\rho_{x}^{z}$. Note that the speed of adjustment in our benchmark economy is rather low (i.e., $\left.\rho_{x}^{z}=0.85\right)$. As indicated by Fig. 7, even small changes in $\rho_{x}^{z}$ lead to sizable welfare costs/gains. On the one hand, increasing adaptation efforts would lower welfare costs more than proportionally. In the extreme case of immediate adjustment $\left(\rho_{x}^{z}=\right.$ 0 ), welfare costs of temperature risk could be reduced to about $0.4 \%$. On the other hand, decreasing adaptation efforts (i.e., $\rho_{x}^{z}>0.9$ ) could have dramatic consequences. Our simple analysis indicates the need of policies that aim at improving agents' ability to adapt faster to temperature shocks. Above all, this goal can be reached by the implementation of new technologies. However, given uncertainty surrounding the real economic impact of climate change, the political, economic and technological mechanisms to abate emissions and thus slow down rising temperatures are still slow (see also Tol, 2002).

In the exercise above, we assume that the speed of adjustment can be reduced immediately and permanently to a chosen value. In what follows, we make the setup more realistic by assuming the speed of adjustment to be stochastic and timevarying. This reflects agents' willingness to modify their adaptation effort over time and uncertainty around the adaptationrelated benefits. Therefore, a stochastic speed of adaptation would introduce an additional type of risk that may have welfare

latter modeling approach involves very high parameter uncertainty as the ongoing climate change is likely to impact future temperature dynamics. In contrast, in our case of a temporary shock, future temperature dynamics do not matter since the shock materializes in the first period only.

21 Recent empirical studies on the potential gains induced by adaptation to climate change in the U.S. are Deschnes and Greenstone (2011), Burke and Emerick (2016) and Park (2016). 


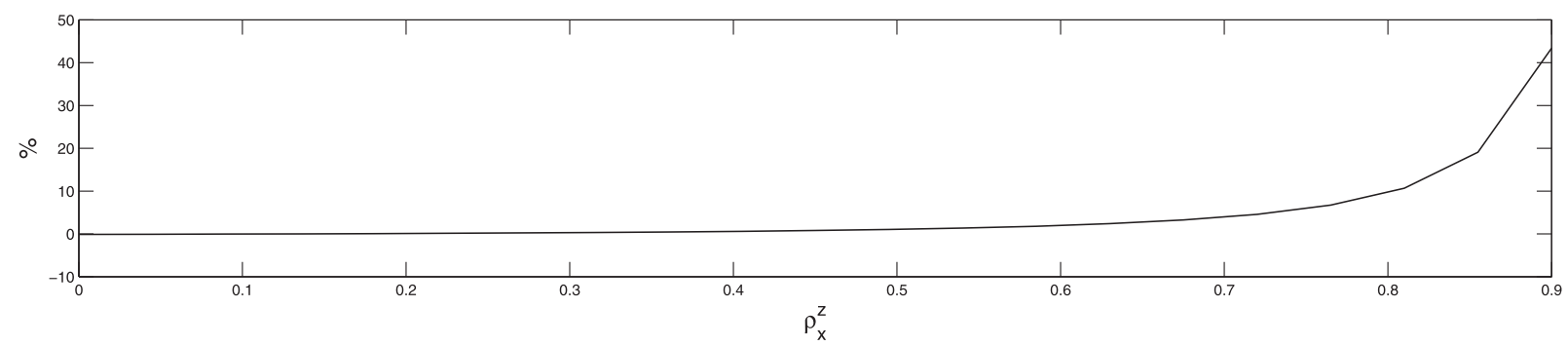

Fig. 7. Welfare costs and speed of adaptation.

Notes: This figure reports welfare costs for different values of $\rho_{x}^{z}$. Welfare costs are computed as in Eq. (6). All the remaining parameters are set to the values shown in Table 1.

Table 7

Welfare costs and "Stochastic" adaptation.

\begin{tabular}{|c|c|c|c|}
\hline & $\begin{array}{c}\mathrm{BC} \\
\left(\tau_{z}=-0.00275\right) \\
{[1]}\end{array}$ & $\begin{array}{c}\text { Temp-effects } \uparrow \\
\left(\tau_{z}=-0.00375\right) \\
{[2]}\end{array}$ & $\begin{array}{c}\text { Adaptation } \\
\sigma_{\Lambda}>0\end{array}$ \\
\hline Panel A: & & & \\
\hline $\begin{array}{l}\rho\left(\epsilon_{z, t}, \epsilon_{\Lambda, t}\right)=0 \\
\text { Panel } \mathrm{B}:\end{array}$ & $18.4 \%$ & $36.8 \%$ & $0.2 \%$ \\
\hline$\rho\left(\epsilon_{z, t}, \epsilon_{\Lambda, t}\right)=-0.99$ & $16.7 \%$ & $34.2 \%$ & $-1.3 \%$ \\
\hline
\end{tabular}

Notes: This table reports welfare costs of temperature risk and stochastic adaptation. Welfare costs of temperature risk are defined as the percentage increase $\Delta>0$ in composite consumption $(\tilde{C})$ that the household should receive in every state and at every point in time in order to be indifferent between living in an economy with full risk exposure (i.e., $\sigma_{z}, \sigma_{a}, \sigma_{x}, \sigma_{\Lambda}>0$ ) and an economy where temperature risk is eliminated (i.e., $\tau_{z}=0$ ). Specification [1] refers to the benchmark calibration (i.e., $\tau_{z}=-0.00275$ ) while specification [2] accounts for higher temperature effects (i.e., $\tau_{z}=-0.00375$ ). The last column displays welfare costs of stochastic speed of adaptation which are defined as the percentage increase $\Delta>0$ in composite consumption $(\tilde{C})$ that the household should receive in every state and at every point in time in order to be indifferent between living in an economy with full risk exposure (i.e., $\sigma_{z}, \sigma_{a}, \sigma_{x}, \sigma_{\Lambda}>0$ ) and an economy where adaptation risk is eliminated (i.e., $\sigma_{\Lambda}=0$ ).

implications. Formally, we augment Eq. (4) by introducing stochastic speed of adaptation:

$$
\begin{aligned}
\Delta a_{t+1} & =\mu_{a}+x_{t}+x_{t+1}^{z}+\sigma_{a} \epsilon_{a, t+1} \\
x_{t} & =\rho x_{t-1}+\sigma_{x} \epsilon_{x, t} \\
x_{t+1}^{z} & =\rho_{x, t}^{z} x_{t}^{z}+\tau_{z} \sigma_{z} \epsilon_{z, t+1} \\
\rho_{x, t}^{z} & =e^{\Lambda_{t}} \rho_{x}^{z} \\
\Lambda_{t} & =\rho_{\Lambda} \Lambda_{t-1}+\sigma_{\Lambda} \epsilon_{\Lambda, t} \\
z_{t+1} & =\mu_{z}+\rho_{z}\left(z_{t}-\mu_{z}\right)+\sigma_{z} \epsilon_{z, t+1} .
\end{aligned}
$$

Hence, the speed of adjustment $\rho_{x, t}^{z}$ fluctuates around $\rho_{x}^{z}$, i.e., the speed of adjustment in our benchmark economy. Note that when $\Lambda_{t}$ is identically equal to zero, $\rho_{x, t}^{z}=\rho_{x}^{z}$. We set the persistence of adaptation shocks, $\rho_{\Lambda}$, to 0.95 (long-lasting adaptation effects) and the volatility, $\sigma_{\Lambda}$, to a small fraction of temperature volatility ( $15 \%$ of $\sigma_{z}$ ).

Welfare costs of both temperature and adaptation risk are presented in Table 7. Two interesting cases worth studying in our model are: (i) shocks to the speed of adaptation that are orthogonal to temperature shocks and (ii) adaptation and temperature innovations are correlated. In Panel A, it is assumed that adaptation shocks are orthogonal, i.e., $\rho\left(\epsilon_{z, t}, \epsilon_{\Lambda, t}\right)=0$, while in Panel B they are assumed to be strongly negatively correlated with temperature shocks, i.e., $\rho\left(\epsilon_{z, t}, \epsilon_{\Lambda, t}\right)=-0.99$. The latter means that agents adjust adaptation effort in response to temperature changes. More specifically, agents increase the speed of adjustment after a positive temperature shock with the aim to reduce the long-lasting adverse effects on productivity.

When time-varying adaptation efforts are independent of temperature changes, they produce small welfare costs of only $0.2 \%$ while the economic losses due to temperature risk remain basically unaffected. Hence, the agent's lifetime utility is not much affected by uncertainty in the speed of adaptation. Different results are obtained once one accounts for a strong link between adaptation and temperature innovations. In this case, a positive shock to temperature triggers increasing speed of adaptation via a reduction in the persistence of temperature effects. This occurs with one lag meaning that agents adjust to temperature changes in the next period. Compared to the case with uncorrelated shocks, welfare costs of temperature risk are reduced by $1.7 \mathrm{pp}$ in the benchmark case and by $2.6 \mathrm{pp}$ when temperature effects are higher. Accordingly, welfare costs of 
stochastic adaptation become negative and amount to $-1.3 \%$ meaning that the lifetime utility of the agent increases when the speed of adaptation reacts in response to temperature shocks. ${ }^{22}$

Our findings suggest that policies aiming at increasing the speed of adaptation can have substantial benefits for social welfare. Modeling the speed of adaptation as an endogenous outcome of agents' decisions, e.g., investments in new technologies, will be an interesting topic for future research. Another important issue that we do not consider is a cost-benefit analysis in which we compare the benefits of adaptation efforts with their costs. Recent research suggests that increasing adaptation efforts may entail substantial costs (see Burke and Emerick, 2016; Park, 2016). Lastly, we do not study other possible adaptation mechanisms in our model. All these aspects are subject to future research.

\section{Concluding remarks}

Our paper represents a first step towards the joint analysis of real business cycles, asset pricing, and temperature changes in one integrated production-based framework. Our approach is motivated by the empirical evidence that shocks to temperature adversely impact TFP growth and a number of key macro-aggregates in the United States. We augment the longrun risk-based production economy of Croce (2014) by time-varying temperature dynamics. An important advantage of our model is its ability to simultaneously match the dynamics of U.S. TFP, temperature, and asset prices. Hence, we are able to quantify the impacts of temperature shocks on both the business cycle and financial markets.

Our results suggest that temperature shocks have a negative impact on both economic activity and financial markets by lowering long-run growth prospects and asset valuations. Over a 50-year horizon, temperature risk leads to non-negligible losses in cumulative output and labor productivity growth. Furthermore, our model shows that the overall welfare costs of temperature risk can amount to $18.4 \%$ of the agent's lifetime utility.

An important driver of welfare costs is the speed of adjustment in response to temperature shocks. Lower welfare costs can be achieved by a faster adaptation to increasing temperatures while a slower adaptation increases welfare costs even more. Most importantly, a permanent change in the speed of adaptation affects welfare costs substantially. In this respect, increasing adaptation efforts can reduce welfare costs to a large extent while decreasing efforts may have drastic consequences for agents' welfare.

Our model is not fully general. For instance, it does not include features such as technological innovation (which might mitigate adverse effects of temperature changes) or social unrest (which might even exacerbate the pure growth and productivity effects we have analyzed here). In the context of adaptation to climate change, the speed of adjustment to temperature increases may be endogenously determined by, e.g., agents' investments in new technologies. Moreover, other adaptation mechanisms such as a gradual reduction in the sensitivity of the economy to temperature shocks should be considered as well. Another important aspect missing in the model are possible feedback effects between technology and temperature dynamics. Such extensions may have important policy implications and are left for future research. Still, we believe that our model allows us to address some of the issues raised by Pindyck (2013) and Revesz et al. (2014) concerning the structure of models designed to measure the economic costs of climate change.

\section{Acknowledgments}

The authors would like to thank B. Ravikumar (co-editor), an associate editor, and two anonymous referees for detailed comments and suggestions. Furthermore our thanks go to Sandra Batten (discussant), Giuliano Curatola, Fulvio Corsi, Patrick Grüning, Scott Kelly, Renatas Kizys, and Antonio Paradiso for their helpful input. We would also like to thank conference/seminar participants at the University of Milan, Bank of Lithuania, CEP-BoE Workshop on Central Banking, Climate Change and Environmental Sustainability, 9th Biennial Conference of the Czech Economic Society, 2017 Royal Economic Society Conference, and University College of Dublin. We gratefully acknowledge research and financial support from SAFE, funded by the State of Hessen initiative for research LOEWE. All errors are ours.

\section{Appendix A. Data}

\section{A.1. Macro quantities}

Real data on GDP, consumption, and investment (in billions of chained (2009) dollars) are obtained from the National Income and Product Accounts (NIPA) data reported by the Bureau of Economic Analysis (BEA) (NIPA Table 1.1.6). Data on labor and labor productivity are retrieved from the FRED, Federal Reserve Bank of St. Louis. Labor is proxied by hours worked in the non-farm business sector [HOANBS] while labor productivity is proxied by real GDP per capita (billions of chained (2009) dollars, [A939RX0Q048SBEA]). Wages are defined as the total wage bill (i.e., the sum of compensation of employees in private industries and supplements to wages, NIPA Table 2.1) divided by the number of private employees

\footnotetext{
22 An alternative way to model adaptation in by introducing a varying coefficient in front of the long-run temperature risk component $x_{t+1}^{z}$. This can be interpreted as adaptation efforts to reduce the impact of temperature shocks on TFP growth. Results are qualitatively similar to our analysis based on changes in the parameters $\tau_{z}$ and $\rho_{x}^{z}$ and available upon request.
} 
(NIPA Table 6.4). Data on Total Factor Productivity (TFP) in the private business sector (excluding government enterprises) are obtained from the Bureau of Labor Statistics (BLS). Data are annual and span the period from 1950 to 2015.

\section{A.2. Asset prices}

The risk-free rate is the one-month Treasury bill rate (from Ibbotson Associates), obtained from the Kenneth-French data library. The market price-dividend ratio is computed from the Robert J. Shiller online stock market dataset. The equity market return is computed from the Standard \& Poor's 500 stock market index (closed-adjusted price), obtained from Yahoo Finance. Nominal prices are converted to real using the personal consumption expenditures deflator which is obtained from the National Income and Product Accounts (NIPA) data reported by the Bureau of Economic Analysis (BEA) (NIPA Table 1.1.9). Data are annual and span the period from 1950 to 2015.

\section{A.3. Temperature and precipitation}

Data on U.S. temperature (expressed in degrees Fahrenheit) and U.S. precipitation (measured in inches) have been retrieved from the NOAA National Centers for Environmental information, Climate at a Glance: U.S. Time Series, from http://www.ncdc.noaa.gov/cag/. Employed temperature and precipitation data are annual and span the period from 1950 to 2015.

\section{Appendix B. Additional empirical evidence}

Table B1

TFP growth dynamics.

\begin{tabular}{|c|c|c|c|c|}
\hline \multirow[b]{2}{*}{ Regressor } & \multicolumn{2}{|c|}{ Period: 1950-2015 } & \multicolumn{2}{|c|}{ Period: 1960-2015 } \\
\hline & (1) & (2) & (3) & (4) \\
\hline \multirow[t]{2}{*}{$\log (P / D)$} & 1.72 & 1.67 & $2.85^{*}$ & $2.60 *$ \\
\hline & [1.27] & [1.28] & [1.49] & [1.52] \\
\hline \multirow[t]{2}{*}{$R_{f}$} & -0.11 & -0.11 & -0.04 & -0.04 \\
\hline & [0.09] & [0.09] & [0.09] & [0.09] \\
\hline \multirow{2}{*}{$\triangle T F P(-1)$} & & 0.04 & & 0.06 \\
\hline & & [0.11] & & [0.13] \\
\hline \multirow[t]{2}{*}{$T$} & $-0.40^{*}$ & $-0.38^{*}$ & $-0.46^{* *}$ & $-0.42^{* *}$ \\
\hline & {$[0.20]$} & [0.19] & {$[0.22]$} & {$[0.20]$} \\
\hline$R^{2}$ & 0.05 & 0.06 & 0.07 & 0.07 \\
\hline
\end{tabular}

Notes: This table presents predictability evidence for TFP growth. Columns (1) and (3) report estimated projection coefficients on the log price-dividend ratio, $\log (P / D)$, the risk-free rate $R_{f}$, and temperature $T$ for the period 1950-2015 and 1960-2015, respectively. Columns (2) and (4) report estimated projection coefficients on the price-dividend ratio, the risk-free rate, lagged TFP growth $\triangle T F P(-1)$, and temperature for the period 1950-2015 and 1960-2015, respectively. Standard errors (reported in square brackets) are computed using the Newey-West var-cov estimator with 3 lags. $* *$ and * denote significance at the $5 \%$ and $10 \%$ level, respectively. TFP growth is computed from the private business sector multifactor productivity index provided by the Bureau of Labor Statistics. The risk-free rate is obtained from the Kenneth-French data library, and the market price-dividend ratio is computed from the Robert J. Shiller online dataset. The U.S. temperature (expressed in degrees Fahrenheit) is from the NOAA National Centers for Environmental Information. The data employed in the regressions are annual and span the period from 1950 to 2015. 

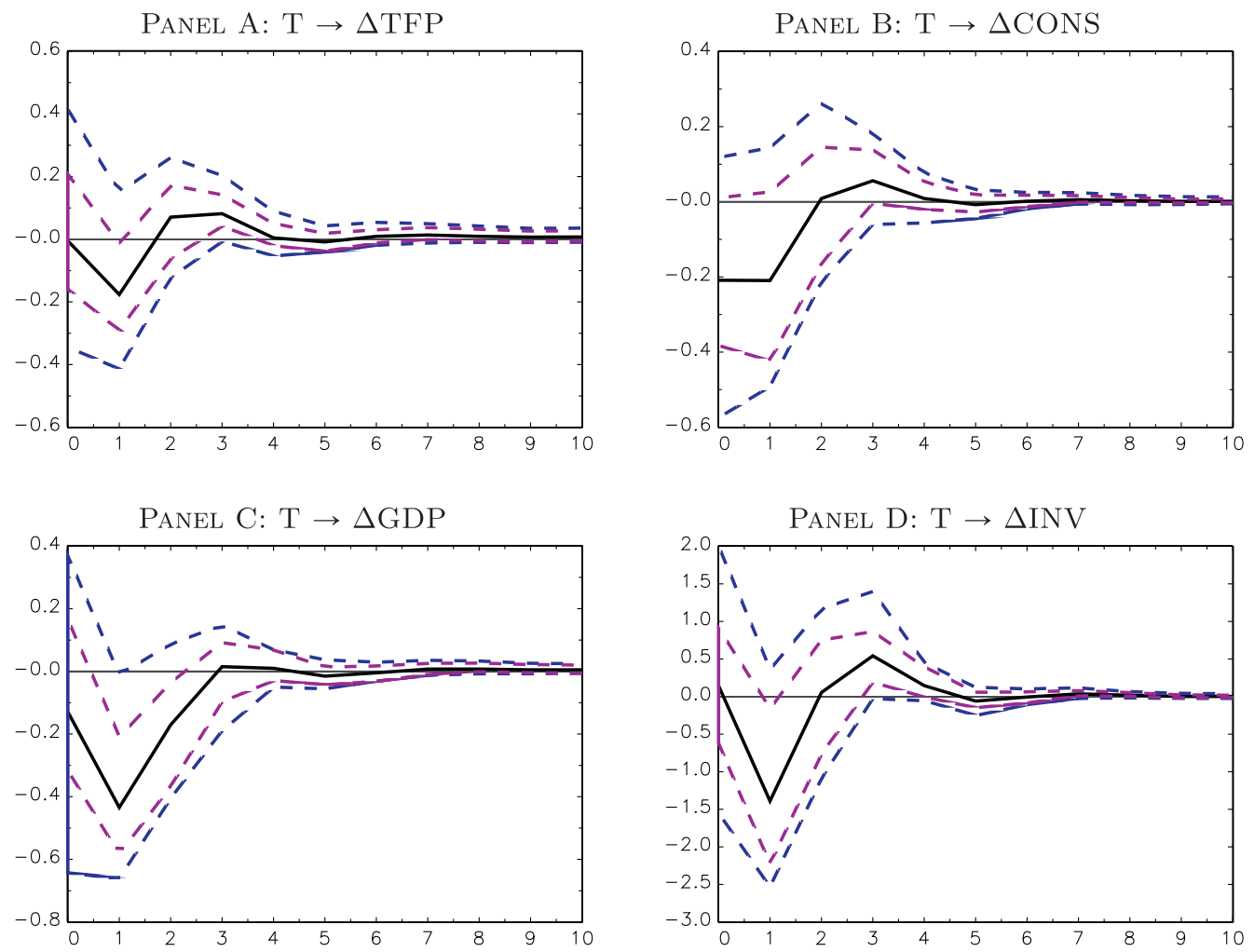

PANEL $\mathrm{E}: \mathrm{T} \rightarrow \Delta \mathrm{LP}$

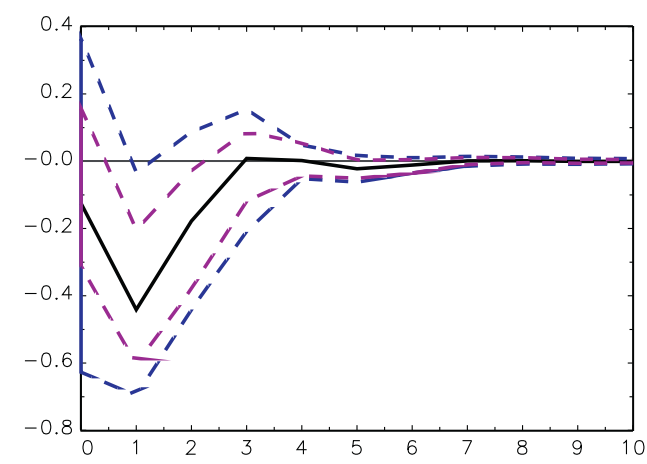

Fig. B1. Impulse response of macro-aggregates to temperature (1950-2007).

Notes: This figure reports "Cholesky" orthogonalized impulse responses of TFP growth (Panel A), consumption growth (Panel B), output growth (Panel C), investment growth (Panel D), and labor productivity growth (Panel E). Solid "black" lines: estimated impulse responses. Dashed "blue" lines: 90\% bootstrapped confidence bands. Dashed "magenta" lines: 68\% bootstrapped confidence bands. The values reported are deviations from the steady state (i.e., long-run mean) in percentage points. The VAR(1) model includes U.S. temperature, TFP growth, consumption growth, GDP growth, investment growth, and labor productivity growth, in this order. A constant is included. TFP growth is computed from the private business sector multifactor productivity index provided by the BLS. All the other macroeconomic variables are taken from the U.S. Bureau of Economic Analysis. The U.S. temperature (expressed in degrees Fahrenheit) is from the NOAA National Centers for Environmental information. Data are annual and span the period from 1950 to 2007 . Additional details on data are given in Appendix A. (For interpretation of the references to color in this figure legend, the reader is referred to the web version of this article.) 

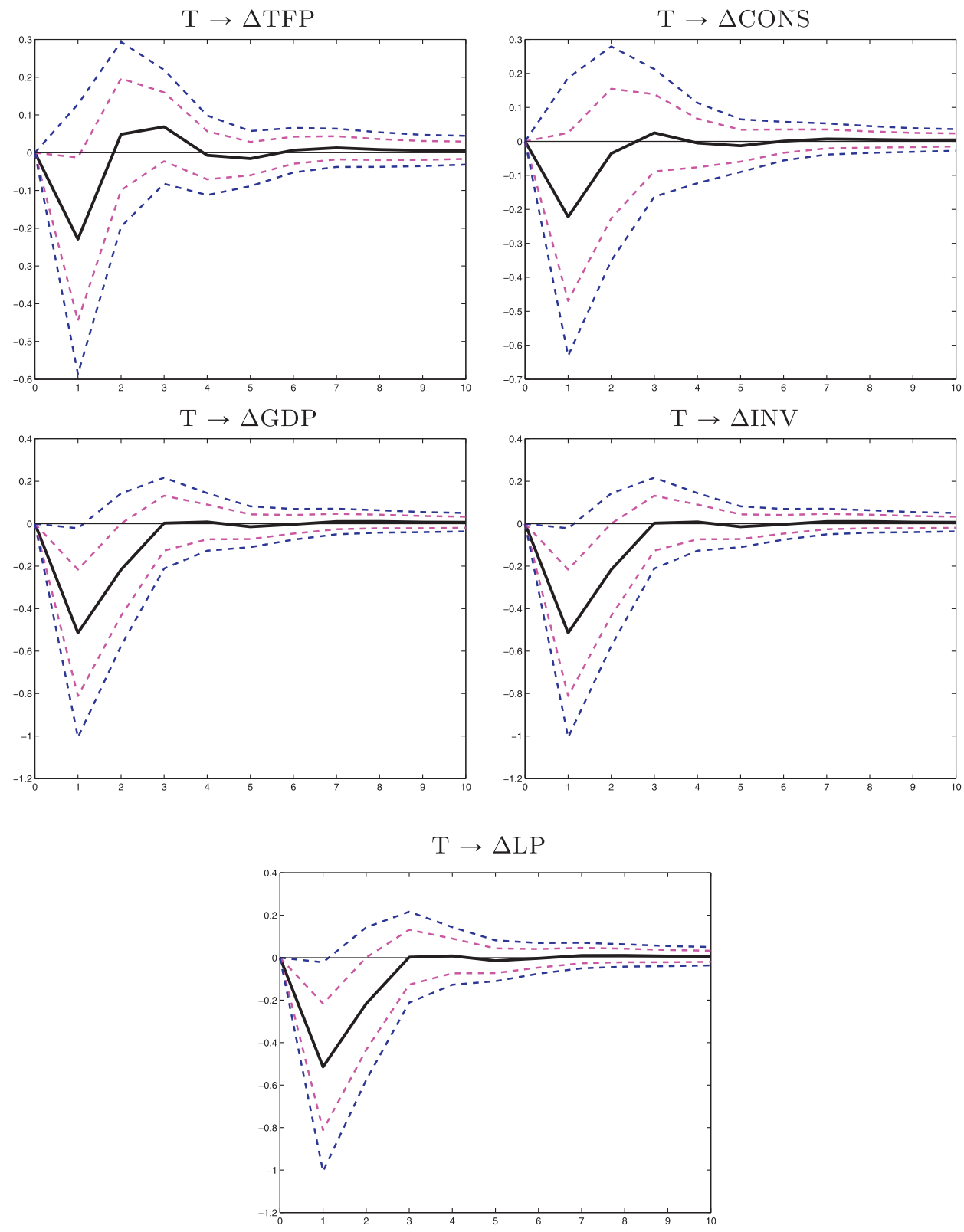

Fig. B2. Generalized impulse responses (macro-aggregates vs. temperature shocks).

Notes: This figure reports the "generalized" impulse responses of TFP, consumption, output, investment, and labor productivity growth to a temperature shock. Solid "black" lines: estimated impulse responses Dashed "blue" lines: 90\% bootstrapped confidence bands. Dashed "magenta" lines: 68\% bootstrapped confidence bands. The values reported are deviations from the steady state (i.e., long-run mean) in percentage points. The VAR(1) model includes U.S. temperature, TFP growth, consumption growth, GDP growth, investment growth, and labor productivity growth. A constant is included. TFP growth is computed from the private business sector multifactor productivity index provided by the Bureau of Labor Statistics. All the other macroeconomic variables are taken from the U.S. Bureau of Economic Analysis. The U.S. temperature (expressed in degrees Fahrenheit) is from the NOAA National Centers for Environmental Information. Data are annual and span the period from 1950 to 2015. Additional details on the data are given in Appendix A. (For interpretation of the references to color in this figure legend, the reader is referred to the web version of this article.) 

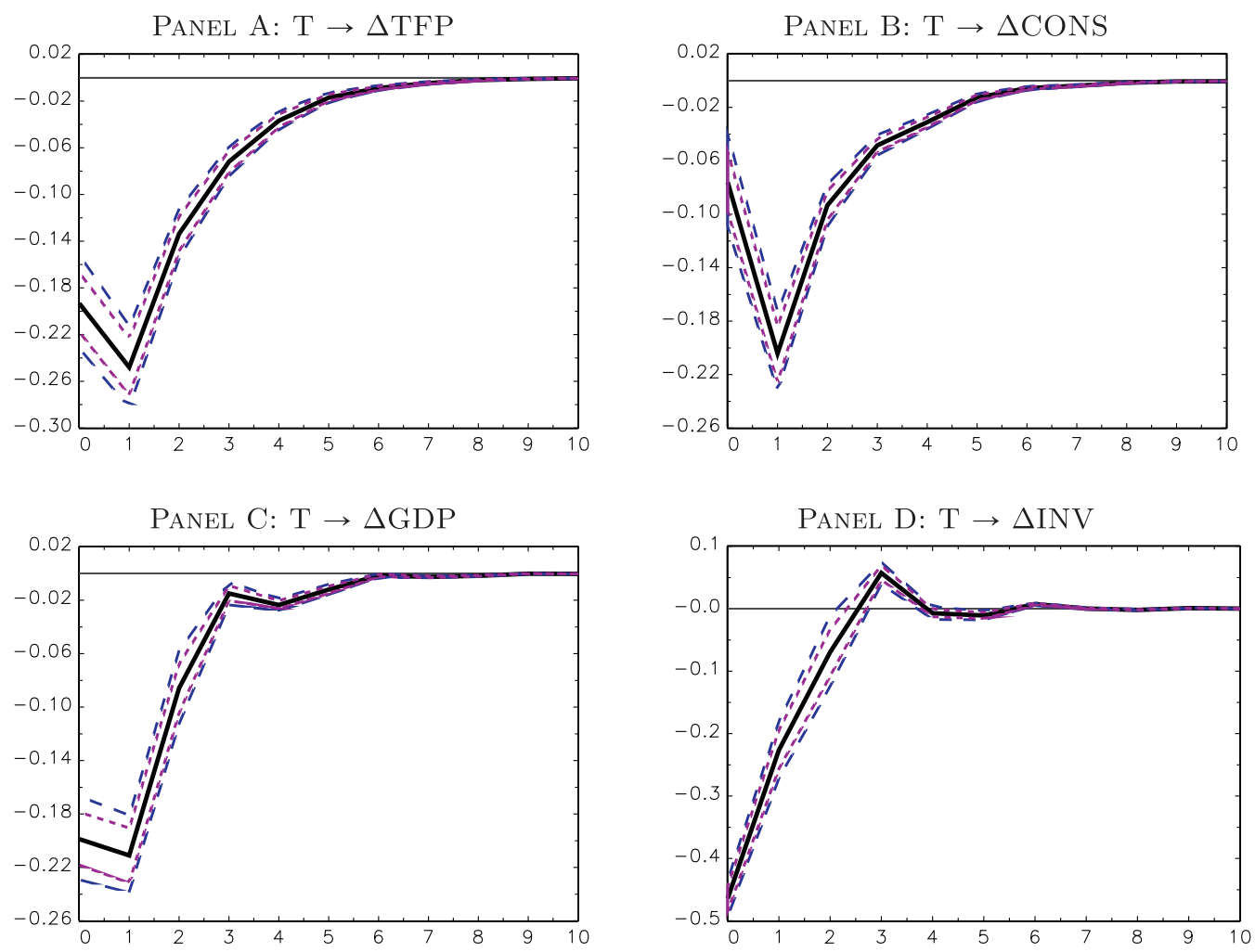

PANEL E: $\mathrm{T} \rightarrow \Delta \mathrm{LP}$

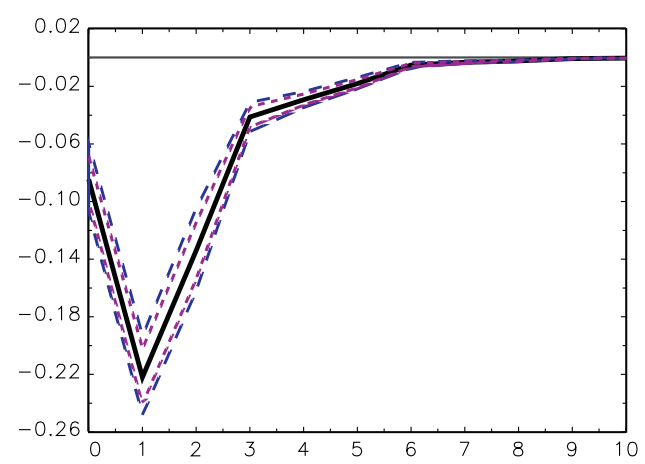

Fig. B3. Model-implied impulse-responses to temperature shocks.

Notes: This figure reports "Cholesky" orthogonalized impulse-responses of TFP growth (Panel A), consumption growth (Panel B), output growth (Panel C), investment growth (Panel D), and labor productivity growth (Panel E) to a temperature shock. Solid "black" lines: estimated impulse responses Dashed "blue" lines: 90\% bootstrapped confidence bands. Dashed "magenta" lines: 68\% bootstrapped confidence bands. The values reported are deviations from the steady state (i.e., long-run mean) in percentage points. The VAR(1) model includes U.S. temperature, TFP growth, consumption growth, GDP growth, investment growth, and labor productivity growth, in this order. A constant is included. All series are obtained from a long sample simulation of 10,000 observations (i.e. 10,000 years). (For interpretation of the references to color in this figure legend, the reader is referred to the web version of this article.) 


\section{Appendix C. Additional quantitative results}

\section{C1. The role of wage rigidities}

In order to account for labor market frictions, we follow Uhlig (2007) and assume that only a fraction of the total labor supply reaches the market at the optimal wage. Formally,

$$
W_{t}=\left(e^{\mu a} W_{t-1}\right)^{\xi}\left(W_{t}^{u}\right)^{1-\xi}
$$

where $\xi$ measures the degree of wage stickiness and $W_{t}^{u}$ represents the frictionless wage as defined by the household's optimal labor allocation

$$
W_{t}^{u}=\frac{1-v}{v}\left(\frac{C_{t}}{1-L_{t}}\right)
$$

Table C1

\begin{tabular}{|c|c|c|c|c|}
\hline Variable & Data & $\mathrm{BC}$ & $\xi=0.35$ & $\xi=0.5$ \\
\hline & & [1] & [2] & [3] \\
\hline \multicolumn{5}{|l|}{ Macro quantities } \\
\hline $\mathbb{E}(\Delta a)$ & 1.30 & 1.33 & 1.33 & 1.33 \\
\hline$A C 1(\Delta a)$ & 0.07 & 0.07 & 0.07 & 0.07 \\
\hline$\sigma(\Delta y)$ & 2.29 & 2.39 & 2.71 & 2.98 \\
\hline$\sigma(\Delta l p)$ & 2.24 & 2.04 & 1.88 & 1.76 \\
\hline$\sigma(\Delta c) / \sigma(\Delta y)$ & 0.79 & 0.82 & 0.87 & 0.90 \\
\hline$\sigma(\Delta i) / \sigma(\Delta y)$ & 4.13 & 1.81 & 1.65 & 1.54 \\
\hline$\sigma(\Delta w) / \sigma(\Delta y)$ & 0.91 & 0.85 & 0.69 & 0.59 \\
\hline$\sigma(\Delta l) / \sigma(\Delta y)$ & 1.12 & 0.32 & 0.41 & 0.52 \\
\hline$\rho(\Delta c, \Delta y)$ & 0.84 & 0.88 & 0.91 & 0.93 \\
\hline$\rho(\Delta c, \Delta i)$ & 0.75 & 0.56 & 0.60 & 0.63 \\
\hline$\rho(\Delta w, \Delta y)$ & 0.30 & 0.95 & 0.95 & 0.91 \\
\hline$\rho(\Delta l, \Delta y)$ & 0.80 & 0.59 & 0.84 & 0.88 \\
\hline$\rho(\Delta l p, \Delta y)$ & 0.99 & 0.95 & 0.95 & 0.91 \\
\hline$\rho(\Delta i, \Delta l)$ & 0.81 & 0.89 & 0.90 & 0.85 \\
\hline \multicolumn{5}{|l|}{ Temperature } \\
\hline $\mathbb{E}(z)$ & 52.43 & 52.43 & 52.43 & 52.43 \\
\hline$\sigma(z)$ & 0.94 & 0.94 & 0.94 & 0.94 \\
\hline$\rho(z, \Delta a)$ & -0.15 & -0.12 & -0.12 & -0.12 \\
\hline$\rho(z, \Delta y)$ & -0.24 & -0.12 & -0.11 & -0.11 \\
\hline \multicolumn{5}{|l|}{ Asset prices } \\
\hline $\mathbb{E}\left(R^{f}\right)$ & 1.23 & 1.23 & 1.17 & 1.11 \\
\hline$\sigma\left(R^{f}\right)$ & 2.16 & 0.70 & 0.90 & 1.13 \\
\hline $\mathbb{E}\left[R^{m}-R^{f}\right]$ & 4.30 & 2.63 & 2.88 & 3.05 \\
\hline$\sigma\left(\mathbb{E}\left[R^{m}-R^{f}\right]\right)$ & 16.80 & 5.45 & 6.09 & 6.56 \\
\hline$\rho\left(z, R^{m}\right)$ & -0.07 & -0.25 & -0.23 & -0.21 \\
\hline
\end{tabular}

Model versus data: macroeconomic quantities and asset prices.

Notes: This table reports the main moments for the benchmark calibration (specification [1]) and two model specifications with wage stickiness. In model [2], we set $\xi=0.35$ as in Uhlig (2007). In model [3], we assume higher wage rigidities by imposing $\xi=0.5$. The aggregate market return is levered as in Croce (2014). Models' entries are obtained from repetitions of small-sample simulations (i.e., averages over 1000 simulations of 100 years). $\mathbb{E}[\cdot], \sigma(\cdot), \rho(\cdot, \cdot)$, and $A C 1(\cdot)$ denote mean, volatility, correlation, and first-order autocorrelation, respectively. Means and volatilities are expressed in percentage points. Data on U.S. temperature and macro-aggregates are from the NOAA National Centers for Environmental information and Bureau of Economic Analysis, respectively. Data are annual and run from 1950 to 2015. Additional details on data are provided in Appendix A.

Table C2

\begin{tabular}{|c|c|c|c|}
\hline$\psi$ & $\begin{array}{c}\text { BC } \\
(\xi=0) \\
{[1]}\end{array}$ & $\begin{array}{c}\text { WR } \\
(\xi=0.35) \\
{[2]}\end{array}$ & $\begin{array}{c}\text { WR } \uparrow \\
(\xi=0.5) \\
{[3]}\end{array}$ \\
\hline 2.00 & $18.4 \%$ & $18.4 \%$ & $18.4 \%$ \\
\hline 0.90 & $6.4 \%$ & $6.4 \%$ & $6.4 \%$ \\
\hline
\end{tabular}

Welfare costs of temp risk: the role of wage rigidities.

Notes: This table reports the welfare costs of temperature risk for two different IES values. Welfare costs are defined as the percentage increase $\Delta>0$ in composite consumption $(\tilde{C})$ that the household should receive in every state and at every point in time in order to be indifferent between living in an economy with full risk exposure (i.e., $\sigma_{z}, \sigma_{a}, \sigma_{x}>0$ ) and an economy where temperature risk is eliminated (i.e., $\tau_{z}=0$ ). Specification [1] refers to the benchmark calibration. In specification [2], we set $\xi=0.35$ as in Uhlig (2007). In specification [3], we assume higher wage rigidities by imposing $\xi=0.5$. 


\section{References}

Allen, M.R. Ingram, W.J., 2009. Constraints on future changes in climate and the hydrologic cycle. Nature 419, $224-232$.

Arsenault, R., 1984. The end of the long hot summer: the air conditioner and southern culture. J. South. Hist. 50 (4), 597-628.

Balvers, R., Du, D., Zhao, X., 2017. Temperature shocks and the cost of equity capital: implications for climate change perceptions. J. Bank. Finance 77, 18-34.

Bansal, R., Kiku, D., Ochoa, M., 2016. Price of Long-Run Temperature Shifts in Capital Markets. Working Paper.

Bansal, R., Kiku, D., Yaron, A., 2007. Risks for the Long Run: Estimation and Inference. Working Paper.

Bansal, R., Ochoa, M., 2011. Welfare Costs of Long-Run Temperature Shifts. Working Paper.

Barlevy, G., 2004. The cost of business cycles under endogenous growth. Am. Econ. Rev. 94 (4), 964-990. doi:10.1257/0002828042002615.

Barrios, S., Bertinelli, L., Strobl., E., 2010. Trends in rainfall and economic growth in africa: a neglected cause of the african growth tragedy. Rev. Econ. Stat. 92 (2), 350-366.

Barrot, J.-N., Sauvagnat, J., 2016. Input specificity and the propagation of idiosyncratic shocks in production networks. Quart. J. Econ. 131 (3), $1543-1592$.

Basu, S., Fernald, J.G., Kimball, M.S., 2006. Are technology improvements contractionary? Am. Econ. Rev. 96 (5), $1418-1448$.

Burke, M., Emerick, K., 2016. Adaptation to climate change: evidence from us agriculture. Am. Econ. J. 8 (3), 106-140. doi:10.1257/pol.20130025.

Cachon, G.P., Gallino, S., Olivares, M., 2012. Severe Weather and Automobile Assembly Productivity. Working Paper.

Cai, Y., Judd, K.L., Lontzek, T.S., 2015. The Social Cost of Carbon with Economic and Climate Risks. Working Paper.

Colacito, R., Hoffmann, B., Phan, T., 2016. Temperature and Growth: A Panel Analysis of the United States. Working Paper.

Croce, M.M., 2006. Welfare Costs and Long-Run Consumption Risk in a Production Economy. Working Paper.

Croce, M.M., 2014. Long-run productivity risk: a new hope for production-based asset pricing? J. Monet. Econ. 66, 13-31.

Dell, M., Jones, B.F., Olken, B.A., 2012. Temperature shocks and economic growth: evidence from the last half century. Am. Econ. J. 4 (3), 66-95. doi:10. 1257/mac.4.3.66.

Deryugina, T., Hsiang, S.M., 2014. Does the Environment Still Matter? Daily Temperature and Income in the United States. National Bureau of Economic Research, Inc. NBER Working Papers 20750.

Deschênes, O., Moretti, E., 2009. Extreme weather events, mortality, and migration. Rev. Econ. Stat. 91 (4), 659-681. doi:10.1162/rest.91.4.659.

Deschnes, O., Greenstone, M., 2011. Climate change, mortality, and adaptation: evidence from annual fluctuations in weather in the US. Am. Econ. J. 3 (4), $152-185$.

Dew-Becker, I., Giglio, S., 2016. Asset pricing in the frequency domain: theory and empirics. Rev. Financ. Stud. 29 (8), $2029-2068$.

Donadelli, M., Grüning, P., 2016. Labor market dynamics, endogenous growth, and asset prices. Econ. Lett. $143,32-37$.

Dua, D., Zhao, X., Huang, R., 2017. The impact of climate change on developed economies. Econ. Lett. 153, 43-46.

Epstein, L., Zin, S., 1989. Substitution, risk aversion, and the temporal behavior of consumption growth and asset returns: a theoretical framework. Econometrica 57 (4), 937-969.

Farmer, J.D., Hepburn, C., Mealy, P., Teytelboym, A., 2015. A third wave in the economics of climate change. Environ. Resour. Econ. 62, $329-357$.

Favilukis, J., Lin, X., 2016. Wage rigidity: a quantitative solution to several asset pricing puzzles. Rev. Financ. Stud. 29 (1), $148-192$.

Golosov, M., Hassler, J., Krusell, P., Tsyvinski, A., 2014. Optimal taxes on fossil fuel in general equilibrium. Econometrica 82 (1), 41-88.

Gomme, P., Ravikumar, B., Rupert, P., 2011. The return to capital and the business cycle. Rev. Econ. Dyn. 14, $262-278$.

Hartmann, D., Klein Tank, A., Rusticucci, M., Alexander, L., Brönnimann, S., Charabi, Y., Dentener, F., Dlugokencky, E., Easterling, D., Kaplan, A., Soden, B., Thorne, P., Wild, M., Zhai, P., 2013. Observations: Atmosphere and Surface. Cambridge University Press, Cambridge, United Kingdom and New York, NY, USA, pp. 159-254.

Hitzemann, S., 2016. Macroeconomic Fluctuations, Oil Supply Shocks, and Equilibrium Oil Futures Prices. Working Paper.

Hitzemann, S., Gao, L., Shaliastovich, I., Xu, L., 2016. Oil Volatility Risk. Working Paper.

Hitzemann, S., Yaron, A., 2016. Welfare Costs of Oil Shocks. Working Paper.

Hsiang, S.M., 2010. Temperatures and cyclones strongly associated with economic production in the Caribbean and Central America. Proc. Natl. Acad. Sci. 107 (35), 15367-15372.

Jermann, U.J., 1998. Asset pricing in production economies. J. Monet. Econ. 41, 257-275.

Kung, H., Schmid, L., 2015. Innovation, growth, and asset prices. J. Finance 70 (3), 1001-1037.

Nordhaus, W.D., 2008. A Question of Balance: Weighing the Options on Global Warming Policies, the Challenge of Global Warming. Economic Models and environmental policy Working Paper.

Oi, W., 1996. The welfare implications of invention. In: Bresnahan, T., Gordon, R. (Eds.), The Economics of New Goods. National Bureau of Economic Research, Inc, pp. 109-142.

Park, J., 2016. Will We Adapt? Temperature Shocks, Labor Productivity, and Adaptation to Climate Change in the United States (1986-2012). Harvard Project on Climate Agreements Discussion Paper Series 2016-81. Harvard University.

Pindyck, R.S., 2013. Climate change policy: what do the models tell us? J. Econ. Lit. 51 (3), 860-872. doi:10.1257/jel.51.3.860.

Revesz, R.L., Howard, P.H., Goulder, L.H., Kopp, R.E., Livermore, M.A., Oppenheimer, M., Sterner, T., 2014. Global warming: improve economic models of climate change. Nature 508, 173-175.

Schlenker, W., Roberts, M.J., 2009. Nonlinear temperature effects indicate severe damages to U.S. crop yields under climate change. Proc. Natl. Acad. Sci. 106 (37), 15594-15598. doi:10.1073/pnas.0906865106.

Segal, G., Shaliastovich, I., Yaron, A., 2015. Good and bad uncertainty: macroeconomic and financial market implications. J. Financ. Econ. 117 (2), 369-397. http://dx.doi.org/10.1016/j.jfineco.2015.05.004.

Solomon, S., Plattner, G.-K., Knutti, R., Friedlingstein, P., 2009. Irreversible climate change due to carbon dioxide emissions. Proc. Natl. Acad. Sci. U.S.A. 106 (6), 1704??-1709.

Stern, N., 2007. The Economics of Climate Change: The Stern Review. Cambridge University Press.

Tol, R., 2002. Estimates of the damage costs of climate change. Part 1: benchmark estimates. Environ. Resour. Econ. 21 (1), 47-73. doi:10.1023/A: 1014500930521.

Uhlig, H., 2007. Explaining asset prices with external habits and wage rigidities in a DSGE model. Am. Econ. Rev. 97 (2), $239-243$.

Villarini, G., Smith, J.A., Vecchi, G.A., 2013. Changing frequency of heavy rainfall over the central united states. J. Clim. 26 (1), $351-357$.

Weitzman, M.L., 2007. A review of "the stern review on the economics of climate change". J. Econ. Lit. 45 (3), $703-724$.

Zivin, J.G., Neidell, M., 2014. Temperature and the allocation of time: implications for climate change. J. Labor Econ. 32 (1), 1-26. 